\title{
ESTUDO SOBRE AS REGIÓES PARA APLICAÇÃO DE INJEÇÃO POR VIA INTRAMUSCULAR *
}

\author{
Brigitta Elza Pfeiffer Castellanos **
}

CASTELLANOS, B. E.P. - Estudo sobre as regiões para aplicação de injeção por via intramuscular. Rev. Esc. Enf. USP, 11 (3): 261-324, 1977.

$A$ administração de medicamentos por via intramuscular (IM) é um procedimento desenvolvido pela enfermagem; a seleção das regiōes a serem utilizadas deve levar em consideração as vantagens $e$ desvantagens de cada um dos locais. Fez-se um levantamento das regiões mais indicadas ou utilizadas pelos enfermeiros-docentes e enfermeiros-hospitalares $e$ do local que indicaram para a punção com a agulha; foi verificado se havia alguma diferenciação na escolha da região de acordo com o sexo $e$ idade do cliente e qual era o conhecimento sobre as contra-indicações $e$ as complicações na utilização de cada uma das regiões para aplicação de injeção IM. Dos dados levantados, concluiu-se que as regiões deltóide, dorso-glútea e face ântero-lateral da coxa são as preferencialmente utilizadas por ambos os grupos, tendo sido constatado que a sua localização nem sempre foi anatomicamente correta e para escolha da região cerca de $80 \%$ da população investigada levou em consideração a idade do cliente. Apenas algumas contraindicações e complicações mencionadas foram concordantes com as analisadas pelos autores consultados; ressalta-se que a região ventroglútea, tida como a mais segura e adequada por estes autores, foi a menos mencionada como utilizada por ambos os grupos de enfermeiros.

* Parte da dissertação de mestrado apresentada à EEUSP, 1977, cuja revisão bibliográfica dos estudos relativos às diferentes regiōes para aplicação de injeção IM encontra-se na Rev. Esc. Enf. USP, 11(2): 85-99, 1977.

** Professor-Assistente da disciplina Enfermagem em Centro Cirúrgico da EEUSP. 


\section{INTRODUÇĀO}

A introdução da injeção intramuscular (IM) na Medicina data dos anos 80 do século passado (Luton, 1882; Soffiantini, 1885; Schadeck, 1886; Balzer e Rebland, 1888)*.

A prescrição de agentes terapêuticos por via intramuscular (IM) é um procedimento comum e atual na moderna prática da medicina, tanto a nível preventivo como a nível curativo.

Cabe à enfermagem administrar a maioria das injeções, por isso é essencial que seus membros conheçam profundamente as implicações da adoção dessa medida terapêutica, a fim de reduzir os vários riscos nela envolvidos. Habilidade num procedimento técnico tal como a injeção IM são obtidas por prática diligente. Para obter resultados apropriados, entretanto, a prática precisa estar baseada em conhecimento científico, e não constituir simplesmente a execução repetida de uma técnica falha. O pessoal de ensino deve estar alerta a este problema para proporcionar orientações e oportunidades adequadas ao aprendizado deste procedimento pelos estudantes de enfermagem. $O$ enfermeiro deve fazer uma análise crítica da técnica que emprega, ou orienta o seu emprego, na aplicação de injeção intramuscular e rever cuidadosamente a anatomia dos locais utilizados, a fim de assegurar uma aplicação segura e habilidosa. Deve, por outro lado, providenciar a continuidade do cuidado, pela inclusão de esquemas de rodízio dos locais de aplicação, no plano de cuidado diário.

CHEZEM (1), estudando o efeito mecânico de injeçōes intramusculares repetidas, provou, através de experiências de laboratório com ratos, que "trauma mecânico ao' tecido muscular, como resultado de injeções IM repetidas de soro fisiológico ( 2 injeções diárias em 6 dias consecutivos), causa uma alteração na estrutura histológica do tecido muscular; a velocidade do clearance do $\mathrm{I}^{131}$ de uma área previamente lesada por repetidas injeções IM é bem menor do que de uma área não lesada." O autor ainda cita outras lesões, tais como:

a - nódulos provocados por soluções não absorvidas ou precipitadas;

- Citado em: HOCHSTETTER, A. Uber Problem und Technik der Intraglutäalen Injektion. Schweiz. Med. Wschr., 85: 1138, 1955. 
b - hematomas resultantes de punções e hemorragias de um vaso sangüíneo;

c - infecções conseqüentes à injeção e

d - tecido fibrótico resultante do processo de reparação do tecido lesado.

Analisando estas lesões, explica que os nódulos, os hematomas e as infecções geralmente são transitórios e, após reabsorção da lesão, parece não haver efeito residual sobre a absorção de substâncias injetadas; lesões fibróticas, entretanto, são de mais longa duração e por isso podem afetar o grau de absorção de uma solução injetada. Neste processo inflamatório há um aumento na vascularização e permeabilidade capilar, tendendo a aumentar o transporte intra-extra vascular; subsequiente proliferação e hialinização de fibras colágenas causam constrição de capilares e pequenos vasos sangüíneos e a formação final de tecido relativamente avascular. Uma vez que ocorreu a cicatrização, a absorção de material injetado no local é reduzida apreciavelmente, como resultado desta diminuição da vascularização. A densidade do tecido fibrótico é outra característica que contribui para a pobreza da dinâmica transcapilar; sua alta densidade e o aumento do ácido hialurônico causam resistência para a disseminação do material injetado através dos planos faciais do tecido, agora, pobremente vascularizado e, por isso, posteriormente reduzindo a área superficial e a velocidade de absorção.

HORTA \& TEIXEIRA (6), estudando os acidentes comuns a todas as vias parenterais, alertam sobre a possibilidade de fenômenos alérgicos serem desencadeados após injeção IM; mencionam o fenômeno de Arthus, ou seja, a reação provocada por injeções repetidas no mesmo local, caracterizada pela não absorção do antígeno, ocasionando infiltração, edema, hemorragia e necrose no ponto de inoculação.

O local adequado para a aplicação da injeção IM é crucial para uma administração segura. HORN (4) refere que na seleção do local deve-se considerar:

a - distância em relação a vasos e nervos importantes;

b - musculatura suficientemente grande para absorver o medicamento;

c - espessura do tecido adiposo;

d - idade do paciente;

e - irritabilidade da droga e

f - atividade do paciente. 
Os locais usuais para a aplicação de injeção IM são: o músculo deltóide (região deltóide $-\mathrm{D}$ ), os músculos da região glútea (região dorso-glútea — DG e região ventro-glútea - VG) e os músculos da face lateral da coxa (região da face ântero-lateral da coxa) FALC).

Empiricamente ou não, todas as regiões citadas vêm sendo utilizadas pela equipe de enfermagem, no atendimento a pacientes que requerem tratamento medicamentoso pela via IM.

Sabemos que as regiões de aplicação de injeção IM devem ser selecionadas de acordo com suas vantagens e desvantagens. São portanto de suma importância: conhecer anatomicamente as regiões utilizadas para poder localizar corretamente o local de aplicação da injeção, estar a par das contra-indicações de cada local e estar alerta às possíveis complicações.

Esse estudo foi, então, elaborado na tentativa de verificar injeção.IM, se existe diferenciação na escolha da região de acordo com a idade e o sexo do cliente e qual o conhecimento que o profissional tem em relação às contra-indicações e complicações de cada uma das regiōes.

\section{OBJETIVOS}

1. Verificar quais as regiões preferenciais e quais os locais mais utilizados para a aplicação de injeções por via intramuscular, pelos enfermeiros-docentes das Escolas de Enfermagem do Município de São Paulo e pelos enfermeiros dos principais hospitais que servem de campo de estágio aos estudantes dessas escolas;

2. Verificar se a idade e o sexo do cliente têm influência na escolha da região para a aplicação da injeção IM;

3. Verificar quais são as complicações e as contra-indicações conhecidas pelos profissionais citados em relação às diferentes regiões, para administração de injeção por via IM.

\section{HIPOTESES}

1. As regiões $\mathrm{D}$ e/ou DG são as preferencialmente utilizadas pelos enfermeiros-docentes das Escolas de Enfermagem do $\mathrm{Mu}$ - 
nicípio de São Paulo e pelos enfermeiros dos hospitais que servem de campo de estágio aos estudantes dessas escolas;

2. Os locais de aplicação das injeções IM, nas diferentes regiões (D, DG, VG e FALC) mais utilizadas ou indicadas pelos enfermeiros-docentes das Escolas de Enfermagem do Município de São Paulo e pelos enfermeiros dos hospitais que servem de campo de estágio aos estudantes dessas escolas, são anatomicamente corretos;

3. A escolha da região para a aplicação de injeção IM segundo os profissionais acima citados depende da idade $\mathrm{e}$ independe do sexo do cliente;

4. Os enfermeiros-docentes das Escolas de Enfermagem do Município de São Paulo e os enfermeiros dos hospitais que -servem de campo de estágio aos estudantes dessas escolas conhecem as contraindicações e complicações de cada região.

\section{MATERIAL E METODO}

\section{POPULAÇÃO}

A população estudada foi constituída de todos os enfermeiros-docentes e enfermeiros-hospitalares que no período da coleta de dados estavam presentes nas instituições selecionadas:

1.1 ENFERMEIROS-DOCENTES das Disciplinas Fundamentos de Enfermagem, Enfermagem Médico-Cirúrgica e Enfermagem Pediátrica de todas as Escolas de Enfermagem do Município de São Paulo:

Escola de Enfermagem da Universidade de São Paulo;

Escola Paulista de Enfermagem;

Faculdade Adventista de Enfermagem e

Faculdade de Enfermagem São José.

Foram escolhidas as disciplinas acima citadas, pois elas oferecem maior oportunidade para orientação e supervisão de aplicação de injeção por via IM. 
1.2 ENFERMEIROS EM SERVIÇO (plantão da manhã e tarde) nas Clínicas Médico-Cirúrgicas e de Especialidades Afins - Nefrologia, Urologia, Neurologia, Reumatologia, Hematologia, e nas Clínicas Pediátricas nos Hospitais do Município de São Paulo que servem como principal campo de estágio aos estudantes de enfermagem das Escolas acima citadas:

Hospital Central da Irmandade da Santa

Casa de Misericórdia;

Hospital das Clínicas da Faculdade de

Medicina da Universidade de São Paulo;

Instituto de Assistência Médica ao Servidor

Público Estadual;

Hospital Emílio Ribas e

Hospital São Paulo.

Selecionamos tais clínicas pois é nelas que é mais freqüente a prescrição de injeção por via IM.

\section{PROCEDIMENTO}

Foi feito o entrosamento inicial com as Escolas de Enfermagem e com os Hospitais. Após a obtenção do consentimento para a realização da pesquisa, foi marcada a data para a entrevista com o chefe de departamento ou de disciplina e com o chefe do Serviço de Enfermagem. Nessa ocasião foram expostos os objetivos e mostrou-se o instrumento de coleta de dados. A data para a distribuição desse instrumento foi marcada de acordo com a disponibilidade de cada setor. A distribuição foi individual e pessoal ou através do chefe de disciplina ou enfermeiro-chefe, conforme a preferência do responsável pelos referidos setores. Quando a entrevista foi efetuada pessoalmente pela pesquisadora, o instrumento foi devolvido no dia seguinte. Nos casos em que o responsável foi o chefe de departamento ou do Serviço de Enfermagem a devolução foi feita em dia previamente marcado. 


\section{INSTRUMENTO DE COLETA DE DADOS}

Tendo-se em vista as características da população, selecionou-se a técnica de questionário para a obtenção das informações (anexo 1).

Antes de sua utilização para a coleta definitiva dos dados esse instrumento foi submetido a um pré-teste para comprovação de sua validade, exigindo modificações para melhor adaptar-se aos objetivos propostos.

\section{CRITERIOS UTILIZADOS PARA A AVALIAÇÃO DAS RESPOSTAS}

Antes da avaliação das respostas ao questionário, estabelecemos os critérios que nortearam o procedimento. São eles:

4.1 Critério utilizado para avaliar as regiões preferencialmente utilizadas pelos enfermeiros-docentes e enfermeiros-hospitalares.

Consideramos como delimitações anatômicas das diferentes regiões para aplicação de injeção IM as seguintes:

REGIAOO GLUTEA (G) - Região limitada superiormente pela crista ilíaca, inferiormente pela prega glútea, medialmente pelo sacro e coccix e lateralmente pelas bordas laterais da coxa e quadril, vistos da face posterior. Inclui os três músculos glúteos (máximo, médio e mínimo) extendendo-se dos quadrantes internos das nádegas ventrolateralmente à espinha ilíaca ântero-superior.

REGIAO DORSO-GLUTEA (DG) - Injeção no glúteo máximo. E o ângulo externo do quadrante superior externo da região glútea (porção superior dorsal dos músculos glúteos). Traça-se uma linha partindo da espinha ilíaca póstero-superior até o grande trocanter do fêmur. Aplicar a injeção na região acima dessa linha, centralmente, com a agulha perpendicular à cama ou onde o individuo está deitado, em decúbito ventral, dirigindo-a ligeiramente à crista ilíaca.

REGIAO VENTRO-GLUTEA (VG) - Injeção no glúteo médio e mínimo. E a região de Hochstetter (porção superior lateral dos 
músculos glúteos). Coloca-se a mão esquerda no quadril direito do cliente. Localizar com a falange distal do dedo indicador esquerdo a espinha ilíaca, espalmando a mão sobre a base do grande trocanter do fêmur e formar com o indicador um triângulo. Aplicar a injeção no centro desse triângulo, com a agulha dirigida ligeiramente para a crista ilíaca. Se a injeção for no lado esquerdo do cliente, colocar o dedo médio na crista ilíaca ântero-superior e depois afastar o dedo indicador para formar o triângulo. Em crianças, colocar o espaço interdigital dos dedos médio e indicador na saliência rolante do grande trocanter. Em caso de mão pequena, colocar o carpo (punho) no grande trocanter, em lugar da mão espalmada.

REGIATO DELTOIDE (D) - Injeção no músculo deltóide. Região compreendida num retângulo na região lateral do braço, iniciando com a extremidade mais inferior do acrômio, devendo-se respeitar a distância de 3 a $5 \mathrm{~cm}$ abaixo do acrômio, e terminando no ponto oposto à axila, a 3 a $3,5 \mathrm{~cm}$ acima da margem inferior do deltóide.

REGIAO DA FACE ANTERO-LATERAL DA COXA (FALC) - Injeção no músculo vasto lateral. Região da face ânterolateral da coxa, delimitada pela linha média anterior da coxa na frente da perna e linha média lateral da coxa do lado da perna, de 12 a $15 \mathrm{~cm}$ abaixo do grande trocanter do fêmur e de 9 a $12 \mathrm{~cm}$ acima do joelho, numa faixa de 7 a $10 \mathrm{~cm}$ de largura. Agulha com um ângulo de cerca de $45^{\circ}$, em direção podálica, de $2,5 \mathrm{~cm}$ de comprimento.

4.2 Critério utilizado para avaliar a correção da indicação do local para a punção da agulha em cada uma das regiões de aplicação de injeção IM.

LOCAL CORRETO — toda indicação dentro dos limites da área demarcada no diagrama.

LOCAL INCORRETO - toda indicação fora dos limites da área demarcada no diagrama. 
FACE ANTERO-LATERAL DA COXA

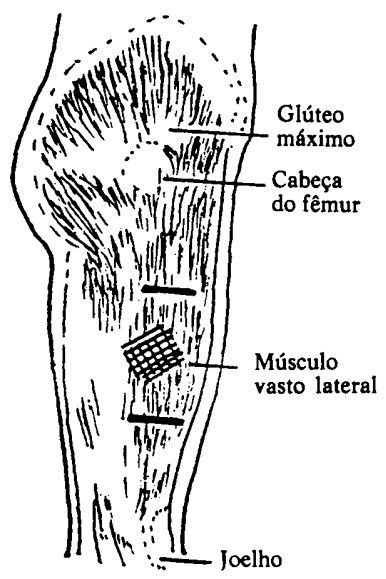

REGIAOO VENTRO.GLOTEA

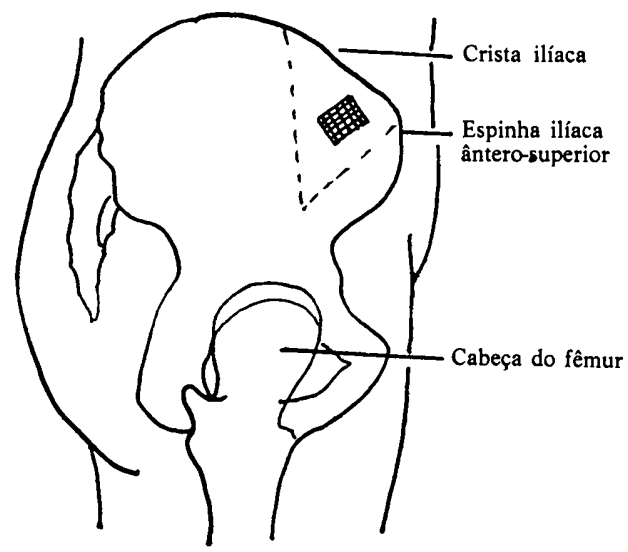

REGIAO DORSO-GLUTEA

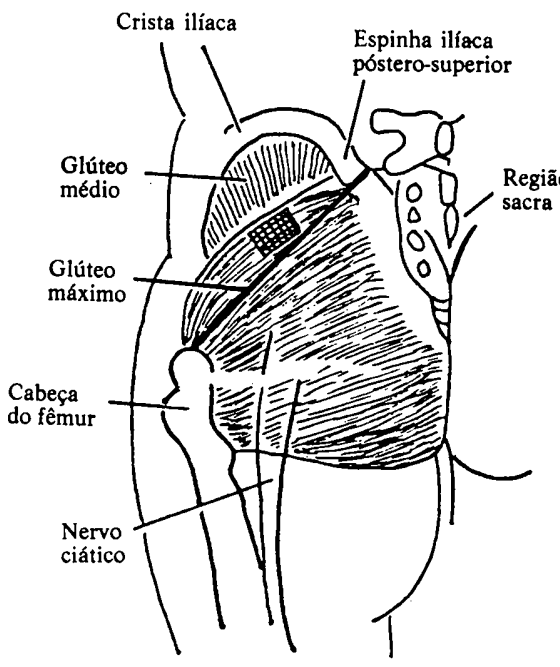

REGIÃO DELTOIDE

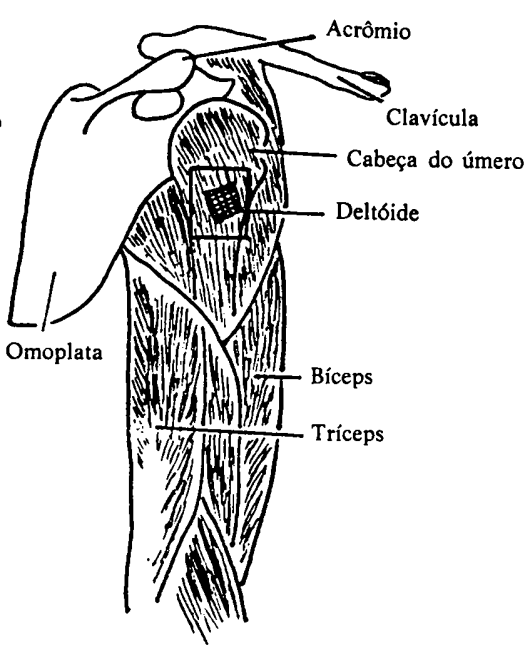


4.3 Critério para classificação dos grupos etários.

Para tabularmos os dados referentes às idades indicadas para cada uma das regióes (questão 8 do questionário), utilizamos 0 critério preconizado por MARCONDES (7):

\begin{tabular}{|c|c|c|c|}
\hline neo-natal .. & 0 & - & \\
\hline infância: lactente & 29 & dias & \\
\hline préescolar & 2 & - & \\
\hline escolar & 7 & - & 1 \\
\hline adolescência: pré-puberal & 10 & - & \\
\hline puberal & 12 & - & \\
\hline pós-puberal & 16 & - & \\
\hline
\end{tabular}

4.4 Critério para avaliar a correção das respostas relacionadas com as contra-indicaşões e complicações de cada uma das regiões definidas anteriormente para aplicação de injeção IM.

Consideramos corretas as que constavam da listagem abaixo citada, elaborada após levantamento de todas as contra-indicações e complicações analisadas pelos diversos autores da bibliografia consultada.

4.4.1 Contra-indicações

Região Deltóide (D)

- Em virtude das características locais:

- dor e sensibilidade local grandes;

- pequeno volume de massa muscular e

- localização de importantes nervos e vasos sangüíneos.

- As contra-indicações são:

- injeções consecutivas;

- volume grande de solução e

- substâncias irritantes.

Região Dorso-Glútea (DG)

- Em virtude das características locais:

- localização do nervo ciático;

- localização de importantes vasos sangüíneos e

- grande espessura do tecido subcutâneo.

- As contra-indicações são:

- utilização do ângulo intęrno do quadrante 
superior externo;

- crianças de 0 a 2 anos de idade;

- agulha com angulação perpendicular à pele;

- agulha curta;

- cliente em decúbito lateral e de pé e

. indivíduos debilitados.

Região Ventro-Glútea (VG)

- por provocar angústia e/ou ansiedade no cliente.

Região da Face Antero-Lateral da Coxa (FALC)

- volume grande da solução;

- injeções consecutivas;

. injeção superficial;

. dor e sensibilidade local grandes;

- recém-nascido;

- angulação da agulha perpendicular à pele e

- tamanho da agulha superior a $2,5 \mathrm{~cm}$.

\subsubsection{Complicações}

Região Deltóide (D)

- lesão dos nervos do feixe vásculo-nervoso;

- lesão do nervo radial;

- lesão da artéria umeral;

- lesão do nervo mediano e ulnar;

- lesão do nervo escapular e axilar e

- infiltrados e nódulos.

Regiāo Dorso-Glútea (DG)

- lesão do nervo ciático com conseqüente paresia, paralisia e defornidades dos membros inferiores;

- lesão de outros nervos;

- infiltrados subcutâneos e

- embolias venosas e arteriais.

Região da Face Antero-Lateral da Coxa (FALC)

- lesão do nervo femoral cutâneo;

- lesão do nervo femoral;

- lesão da artéria femoral superficial;

- contratura do quadríceps femoral;

- fibrose local e

. infiltrados. 


\section{APRESENTAÇÃO, ANĀLISE E DISCUSSÃO DOS RESULTADOS}

Optamos por apresentar os resultados juntamente com sua análise e discussão, para maior facilidade da compreensão desse estudo. Para tanto dividiremos este capítulo em cinco partes a saber:

1. quanto às regiões utilizadas ou indicadas para a administração de injeção por via IM;

2. quanto ao local exato da punção da agulha em cada uma das regiões de aplicação de injeção IM;

3. quanto à diferenciação na escolha da região de aplicação de injeção IM de acordo com o sexo e a idade do cliente;

4. quanto ao conhecimento de contra-indicações na utilização de cada uma das regiões de aplicação de injeção IM e

5. quanto ao conhecimento de complicações conseqüentes à utilização de cada uma das regiōes de aplicação de injeção IM.

$O$ total de enfermeiros-docentes participantes do presente estudo foi 48 e de enfermeiros-hospitalares, 156. Os dados, apresentados em tabelas, referentes aos enfermeiros-docentes receberão a alínea "a" e os referentes aos enfermeiros-hospitalares a alínea "b", na numeração das referidas tabelas.

1. QUANTO ȦS REGIOES UTILIZADAS OU INDICADAS PARA A ADMINISTRAÇÃO DE INJEÇÃO POR VIA INTRAMUSCULAR

Nas tabelas I-a e I-b foram colocados os números e as porcentagens dos enfermeiros-docentes e enfermeiros-hospitalares que utilizam cada região.

Nota-se nas tabelas I-a e I-b, que as regiões D, DG e FALC são as mais utilizadas pelos enfermeiros-docentes nas proporções de $89,58 \%, 85,42 \%$ e $89,58 \%$, respectivamente. Os enfermeiros-hospitalares deram preferência à região $\mathrm{D}(96,13 \%)$, seguida da região DG $(79,35 \%)$ e da FALC $(60,65 \%)$.

A utilização tão freqüente da região $D$ (em média * $94,66 \%$ ) se deve, provavelmente, ao apego à tradição e talvez à faci- 
TABELA I-a - Distribuição do nümero e porcentagen dos enfermeiros-do centes segundo as regiōes de aplicação de injeção IM e respectiva utilização.

\begin{tabular}{|c|c|c|c|c|c|c|c|c|}
\hline \multirow{2}{*}{$\begin{array}{r}\text { REGIAO } \\
\text { UTILIZAÇAONTE }\end{array}$} & \multicolumn{2}{|r|}{ D } & \multicolumn{2}{|r|}{ DG } & \multicolumn{2}{|c|}{ VG } & \multicolumn{2}{|c|}{ FALC } \\
\hline & $\mathbf{N}$ & 8 & $N$ & 1 & $\mathbf{N}$ & 8 & $\mathrm{~N}$ & 8 \\
\hline SIM & 43 & 89,58 & 41 & 85,42 & 21 & 43,75 & 43 & 89,58 \\
\hline NÃO & 5 & 10,42 & 7 & 14,58 & 27 & 56,25 & 5 & 10,42 \\
\hline TOTAL & 48 & 100,00 & 48 & 100,00 & 48 & 100,00 & 48 & 100,00 \\
\hline
\end{tabular}

D = Região deltóide

DG = Regiäo dorso-glütea

VG = Região ventro-glútea

FALCì Região face ântero-lateral da coxa

TABELA I-b - Distribulģão do nümero - porcentagen dos enfermeiroshospitalares segundo as regiōes de aplioação de inje gão IM - respectiva utilização.

\begin{tabular}{|c|c|c|c|c|c|c|c|c|}
\hline \multirow{2}{*}{$\underbrace{\text { REGIKIRO IRO }}_{\text {UTILIZAÇAO }}$} & \multicolumn{2}{|r|}{ D } & \multicolumn{2}{|c|}{ DG } & \multicolumn{2}{|c|}{ V,G } & \multicolumn{2}{|c|}{ FALC } \\
\hline & N & 1 & N & 1 & $N$ & 8 & N & 8 \\
\hline SIM & 149 & 96,13 & 123 & 79,35 & 2 & 1,29 & 94 & 60,65 \\
\hline NAO & 6 & 3,87 & 32 & 20,65 & 153 & 98,71 & 61 & 39,35 \\
\hline TOTAL & $155 *$ & 100,00 & 155 * & 100,00 & $155^{\star}$ & 100,00 & $155^{\star}$ & 100,00 \\
\hline
\end{tabular}

- Un (1) enfermelro não respondeu

D = Região deltöide

$D G=$ Região dorso-glūtea

VG = Região ventro-glütea

FALC = Região face ântero-lateral da coxa 
lidade de acesso, pois ela é aconselhada por bem poucos autores e mesmo estes fazem-lhe sérias ressalvas, tais como: impossibilidade de ser utilizada para substâncias irritantes, aplicações consecutivas e volumes grandes de soluções, devido à sua massa muscular relativamente pequena, perigo de lesão de ramos do feixe vásculo-nervoso local por variações anatômicas individuais e lesão do nervo radial, mediano e ulnar por injeção mal localizada ou difusão da droga.

A região $D G$, bastante indicada pelos enfermeiros-docentes $(85,42 \%)$ e pelos enfermeiros-hospitalares $(79,35 \%)$, é igualmente aconselhada por diversos autores, principalmente devido à boa espessura do músculo para receber o líquido injetado e boa absorção do medicamento. A não utilização desta região por alguns enfermeiros-docentes $(14,58 \%)$ e hospitalares $(20,65 \%)$ pode estar relacionada com as possíveis complicações vasculares e nervosas principalmente lesão do nervo ciático.

A região $F A L C$, escolhida em $2 .^{\circ}$ lugar pelos enfermeiros-docentes $(89,58 \%)$ e em $3 .^{\circ}$ lugar pelos enfermeiros-hospitalares $(60,65 \%)$, tem igualmente vários estudiosos adeptos, por ser considerada como uma área livre de vasos e troncos nervosos importantes e por ter extensa área de aplicação. A não utilização dessa região por alguns enfermeiros-docentes $(10,42 \%)$ e enfermeiros-hospitalares $(39,35 \%)$ talvez se deva ao fato de não estar totalmente livre de riscos, podendo apresentar complicações tais como contratura do quadríceps femoral, lesão do nervo femoral cutâneo, lesão do nervo femoral e fibrose local.

Analisando ainda as tabelas I-a e I-b verificamos que a região $V G$ é a que menos foi mencionada, sendo pouco utilizada pelos enfermeiros-docentes $(43,75 \%)$ e quase não utilizada pelos enfermeiroshospitalares $(1,29 \%)$, apesar de vários autores considerarem esta região como a melhor existente, por ser a única realmente segura devido à ausência de qualquer vaso ou nervo importante e à pequena espessura de seu tecido subcutâneo. A pobreza da bibliografia nacional relacionada com a utilização desta região pode talvez explicar sua pouca utilização.

Nas tabelas II-a e II-b foram agrupados os enfermeirosdocentes e hospitalares que conhecem ou não todas as regiões de aplicação de injeção IM.

- média ponderada. 
TABELA II-a - Distribuição do número e porcentagem dos enfermeiros-docentes, segundo o conhecimento ou não de todas as regiōes indicadas para a aplicação de injeção IM.

\begin{tabular}{c|cc}
\hline \multirow{2}{*}{ CONHECIMENTO } & \multicolumn{2}{|c}{ ENFERMEIRO-DOCENTE } \\
& $\mathrm{N}$ & $\%$ \\
\hline SIM & 34 & 70,83 \\
NAO & 14 & 29,17 \\
\hline TOTAL & 48 & 100,00 \\
\hline
\end{tabular}

TABELA II-b - Distribuição do número e porcentagem dos enfermeiros-hospitalares, segundo o conhecimento ou não de todas as regiões indicadas para a aplicação de injeção IM.

\begin{tabular}{l|cc}
\hline \multirow{2}{*}{ CONHECIMENTO } & \multicolumn{2}{|c}{ ENFERMEIRO-HOSPITALAR } \\
& $\mathrm{N}$ & $\%$ \\
\hline SIM & 52 & 33,33 \\
NĀO & 96 & 61,54 \\
NR & 8 & 5,13 \\
\hline TOTAL & 156 & 100,00 \\
\hline
\end{tabular}

$\mathrm{NR}=$ Não respondeu

Consultando as tabelas II-a e II-b, observamos que pouco mais de $1 / 4$ dos enfermeiros-docentes $(29,17 \%)$ e pouco mais da metade dos enfermeiros-hospitalares $(61,54 \%)$ não conheciam algumas regiōes que podem ser utilizadas para a aplicação de injeção IM.

Consultando os dados referentes às regiões não conhecidas (questão 4 do questionário), verificamos que, do total de 14 enfermeiros-docentes que não conheciam todas as regiões para aplicação de 
injeção IM, 1 (2,09\% da população total) não conhecia a região DG e 13 (27,08\% da população total) a região VG e do total de 96 enfermeiros-hospitalares que desconheciam algumas regiões, $5 \quad(3,21 \%$ da população total) não conheciam a região $\mathrm{DG}, 95(60,90 \%$ da população total) a VG e 2 (1,28\% da população total) a FALC.

$O$ fato de ser a região VG mais conhecida pelos enfermeiros-docentes $(72,92 \%)$ do que pelos enfermeiros-hospitalares $(39,10 \%)$ pode ser explicado pelo fato de ter o corpo docente maiores oportunidades de manter-se em dia com a bibliografia atual, sobretudo no que diz respeito a revistas estrangeiras.

$\mathrm{Na}$ tabela III-a foram colocados o número e a porcentagem das regiões conhecidas e utilizadas pelos enfermeiros-docentes, bem como das regiões conhecidas, mas não utilizadas pelos mesmos enfermeiros.

Consultando os dados da tabela III-a verificamos que dos 48 enfermeiros-docentes, $15(31,25 \%)$ conhecem determinada região, mas não a utilizam. Analisando os dados obtidos, referentes a essas regiões conhecidas, mas não utilizadas (questão 10 do questionário), verificamos que a região VG é a menos utilizada pois 14 desses 15 do-

TABELA III-a - Distribuição do número e porcentagem dos enfermeiros-docentes, segundo o conhecimento e utilização das regiões indicadas para a aplicação de injeção IM.

\begin{tabular}{c|cc}
\hline \multirow{2}{*}{ REGIÃO } & ENFERMEIRO-DOCENTE \\
$\mathrm{N}$ & $\%$ \\
\hline $\begin{array}{c}\text { CONHECIDA } \\
\text { UTILIZADA } \\
\text { CONHECIDA } \\
\text { MAS NÃO } \\
\text { UTILIZADA }\end{array}$ & 33 & 68,75 \\
\hline TOTAL & 48 & 31,25 \\
\hline
\end{tabular}


centes $(29,17 \%$ da população total) nảo a utilizam; as razões dadas para a sua não utilização foram: falta de conhecimento e de segurança suficientes $-5(10,42 \%)$; falta de oportunidade $-4(8,33 \%)$; não houve necessidade $(1-2,08 \%)$; clientes queixavam-se de dor -1 $(2,08 \%)$; clientes não acetiavam $-1(2,08 \%)$; dois docentes não responderam a essa questão.

A região $F A L C$ foi citada apenas por 5 enfermeiros-docentes $(10,42 \%)$. Um deles $(2,08 \%)$ preferiu não utilizá-la, porque os clientes queixavam-se de dor e quatro $(8,33 \%)$ não responderam a essa questão.

Como fonte de informação sobre as regiões conhecidas mas não utilizadas pelos enfermeiros-docentes, foram mencionadas: informação oral $-5(10,42 \%)$; observação de alguém utilizando-a -2 $(4,16 \%)$; publicação a seu respeito $-11(22,92 \%)$; estudo de anatomia $-1(2,08 \%)$.

$\mathrm{Na}$ tabela III-b encontram-se o número e a porcentagem das regiões conhecidas e utilizadas pelos enfermeiros-hospitalares e das regiões conhecidas, mas não utilizadas pelos mesmos enfermeiros.

Com relação ao dados sobre os enfermeiros-hospitalares (tabela III-b), verificamos que, dos 156, 59 (37,82\%) conhecem mas não utilizam determinada região. Os dados obtidos referentes a essas regiões (questão 10 do questionário) mostram que 6 enfermeiros $(3,85 \%$ da população total) conhecem mas não utilizam a região D, 27 (17,31\% da população total) a região DG e $59(37,82 \%$ da população total) as regiōes VG e FALC. As razões dadas para a não utilização da região VG foram: por achar desnecessário - $27(17,31 \%)$; por falta de oportunidade - $11(7,05 \%)$; por achar outros locais mais seguros e menos dolorosos - $4(2,56 \%)$; por achar necessário maior esclarecimento sobre o assunto - $6(3,85 \%)$; preferência individual do paciente e costume pessoal $-1(0,64 \%)$; dez enfermeiros $(6,41 \%)$ não responderam a essa questão.

Para a região $F A L C$ foram dados os seguintes motivos: por ser muito dolorosa $-11(7,05 \%)$; foi desnecessário - 12 $(7,69 \%)$; por não ser região apropriada $-1(0,64 \%)$; por falta de oportunidade $-4(2,56 \%)$; por achar os outros locais mais seguros $2(1,28 \%)$; trinta e nove enfermeiros $(25 \%)$ não responderam a essa pergunta. 
Para a região $D G$ foram referidos como justificativa por sua não utilização: falta de oportunidade $-1(0,64 \%)$; facilidade em utilizar outros locais $-1(0,64 \%)$; por achar outros locais mais seguros $-1(0,64 \%)$; porque foi desnecessário - $1(0,64 \%)$; vinte e três $(14,74 \%)$ enfermeiros não deram resposta a essa pergunta.

TABELA III-b - Distribuição do número e porcentagem dos enfermeiros-hospitalares, segundo o conhecimento e utilização das regiões indicadas para a aplicação de injeção IM.

\begin{tabular}{|c|c|c|}
\hline \multirow{2}{*}{ REGIĀO } & \multicolumn{2}{|c|}{ ENFERMEIRO-HOSPITALAR } \\
\hline & $\mathbf{N}$ & $\%$ \\
\hline $\begin{array}{c}\text { CONHECIDA } \\
\text { E } \\
\text { UTILIZADA }\end{array}$ & 97 & 62,18 \\
\hline $\begin{array}{c}\text { CONHECIDA } \\
\text { MAS NÃO } \\
\text { UTILIZADA }\end{array}$ & 59 & 37,82 \\
\hline TOTAL & 156 & 100,00 \\
\hline
\end{tabular}

Para a região $D$ o motivo dado para sua não utilização foi: haver outras regiões mais seguras - $4(2,56 \%)$; dois $(1,28 \%)$ enfermeiros não responderam a essa questão.

As fontes de informação sobre tais regiões, conhecidas mas não utilizadas, foram: informação oral - 41 (26,28\%); observação de alguém utilizando-a $-10(6,41 \%)$; publicação a seu respeito $-8(5,13 \%)$.

Analisando globalmente as razões apresentadas pelos enfermeiros-docentes e hospitalares para a não utilização da região VG, concluímos que a falta de conhecimento e conseqüente insegurança foram os motivos principais. Isto é compreensível, pois a bibliografia em português é bem escassa e, pelos dados obtidos dos enfermeiros-docentes, $13(27,08 \%)$ não a conhecem (tabela II-a) e $14(29,17 \%)$ a conhe- 
cem mas não a utilizam (tabela III-a), perfazendo um total de $56,25 \%$ de enfermeiros-docentes que não utilizam essa região, o que leva a um círculo vicioso: a falta de conhecimento leva à não utilização. Dessa maneira o enfermeiro-docente não orienta como utilizar a região com consequiente falta de utilização pelos enfermeiros-hospitalares.

Além disso, o apego às localizações tradicionais é universal e a própria insegurança o alimenta. WEMPE (11) relata sua experiência de introdução dessa região na rotina hospitalar: "sua adoção por parte das enfermeiras foi um processo gradual, pois houve necessidade de ajudá-las a superar a preferência pela tradição e resistência à mudança; no início enfatizamos que o uso desta região era seguro e, posteriormente, demos cuidadosa instrução e supervisionamos sua prática para diminuir seus sentimentos de insegurança. Após algum tempo de uso as enfermeiras começaram a utilizar essa região".

ZELMAN (12) descreve a introdução dessa região no Serviço Médico do Hospital da Administração dos Veteranos, em Topeka, Kansas, USA, em maio de 1959: "aprendendo a técnica as enfermeiras tornaram-se entusiasmadas com suas vantagens em não ter que virar os pacientes e com a acentuada redução do número de detalhes de técnica requeridos; com a experiência cada vez maior, os pacientes se beneficiaram com a ausência de lesões nervosas envolvendo os membros inferiores e de sequielas tais como infiltrados subcutâneos dolorosos c desconforto ao se deitarem sobre seus glúteos doloridos; se bem que tenha havido um programa enérgico de ensino e encorajamento para implementar a nova técnica, sua disseminação pelas outras clínicas deste Hospital foi iniciada pelo Serviço de Enfermagem como resultado do entusiasmo dos enfermeiros do Serviço Médico. Em quase dois anos de experiência com este método não encontramos morbidade".

Com relação à não aceitação do doente e a queixa de sensação dolorosa, igualmente citados como justificativas para a não utilização da região VG, encontramos também referência a estas situações nos estudos de SCHMIDT (8) o qual conclui que a intensidade e duração da dor eram aproximadamente a mesma em ambos os locais região DG e VG. WEMPE (11) menciona que, em sua experiência, inicialmente os pacientes mostravam-se apreensivos quanto ao uso da nova área; para minimizar seu medo lhes foi dada cuidadosa orientação 
e apoio; após a primeira injeção a maioria preferiu esse local; pacientes com injeções diárias consecutivas eram especialmente favoráveis e pacientes que precisavam ou costumavam deitar-se em decúbito dorsal pareciam que sentiam-se mais confortáveis com a utilização desse novo local.

Partindo da análise dos motivos dados pelos enfermeirosdocentes e enfermeiros-hospitalares para a não utilização da região FALC, verificamos que o costume, a falta de segurança e a dor foram mencionados. A maior sensação dolorosa na utilização dessa região se deve à lesão do nervo femoral cutâneo, razão pela qual muitos clientes recusam injeções nessa região. $O$ tradicionalismo e a escassa bibliografia nacional talvez possam explicar o apego ao costume de utilizar outras regiões, geralmente as $\mathrm{D}$ e DG.

A não utilização das regiões $D$, DG e FALC, por existirem outras regiões mais seguras, pode estar relacionada com o conhecimento de suas contra-indicações e complicações; a região $\mathrm{D}$ deverá ser unicamente utilizada em casos de inoculações em massa, extensas áreas de queimaduras ou outras lesões dérmicas ou quando for necessário incluí-la no esquema de rodízio de grande número de injeções. Ressalta-se ainda que o líquido a ser administrado não poderá ser irritante nem exceder a $4 \mathrm{ml}$. A região DG não deve ser utilizada para recém-nascidos e lactentes, indivíduos debilitados e caquéticos em virtude do perigo de lesão do nervo ciático. Sua utilização para os demais clientes deverá levar em consideração o estrito respeito às demarcações de seus limites anatômicos e às características da agulha, ou seja, tamanho de acordo com a espessura do panículo adiposo e angulação perpendicular à superfície onde o paciente está deitado, em decúbito ventral.

A região FALC não é aconselhada para recém-nascidos, pois poderá haver lesão da artéria femoral e contratura do quadríceps femoral; a possibilidade de haver dor e fibrose local deverá ser levada em consideração na avaliação de sua indicação para adultos.

2. QUANTO AO L̇OCAL EXATO DA PUNÇÃO DA AGULHA EM
CADA UMA DAS REGIÓES DE APLICAÇÃO DE INJEÇÃO IM

Nas tabelas IV-a e IV-b foram agrupados os enfermeirosdocentes e hospitalares que localizaram corretamente ou incorretamente 
o local da punção em cada uma das regiões para aplicação de injeção IM.

Pelos dados expostos nas tabelas IV-a e IV-b, verificamos que dos 48 enfermeiros-docentes que citaram utilizar uma ou mais das 4 regiões indicadas para a aplicação de injeção IM, houve maior proporção de docentes $(68,92 \%)^{*}$ que assinalaram o local de aplicação corretamente. $\mathrm{O}$ mesmo aconteceu com os enfermeiros-hospitalares, mas com menor porcentagem de acerto $(64,68 \%)$.* $^{*}$

O local da introdução da agulha na região $D$, utilizada por $89,58 \%$ dos enfermeiros-docentes e por $96,13 \%$ dos enfermeiros-hospitalares (tabelas I-a e I-b), foi corretamente localizado por $35(81,40 \%$ - 72,92\% da população total) enfermeiros-docentes e por 116 $(77,85 \%-74,36 \%$ da população total) enfermeiros-hospitalares e incorretamente por $4(9,30 \%-8,33 \%$ da população total) dos enfermeiros-docentes e $5(3,36 \%-3,21 \%$ da população total $)$ dos enfermeiros-hospitalares. Tais dados sugerem que apesar de ser esta uma região universal e assiduamente utilizada, também é passível de receber injeções inadequadamente localizadas e de conseqüentes complicações.

A punção da região $D G$, utilizada por $85,42 \%$ dos enfermeiros-docentes e por $\mathbf{7 9 , 3 5 \%}$ dos enfermeiros-hospitalares (tabelas I-a e I-b) foi localizada com correção por quase $2 / 3(63,41 \%-54,17 \%$ da população total) dos enfermeiros-docentes e enfermeiros-hospitalares $(64,23 \%-50,64 \%$ da população total $)$, e de maneira incorreta por menos de $1 / 3(29,27 \%$ - $25 \%$ da população total $)$ dos enfermeirosdocentes e $1 / 4(24,39 \%$ - $19,23 \%$ da população total $)$ dos enfermeiros-hospitalares, cifras estas superiores às da localização incorreta na região $\mathrm{D}$. Na utilização de tal região é de suma importância o respeito às demarcações dos limites anatômicos; qualquer injeção abaixo da linha de conexão da espinha ilíaca póstero-superior ao grande trocanter foi considerada incorretamente localizada e é passível de provocar seríssimas complicações; a localização da punção fora da área recomendada para a região DG converterá a injeção em "glútea", que é amplamente contra-indicada por uma série de autores em virtude da possibilidade de lesōes do nervo ciático.

* dados obtidos calculando-se a porcentagem de respostas corretas em relação ao número de respostas totais. 
TABELA IV-a - Distribuição do nümero e porcentagem dos enfermeiros-do centes, segundo a resposta dada em relação ao local de aplicação de injeção IM nas diferentes regiōes utiliza das.

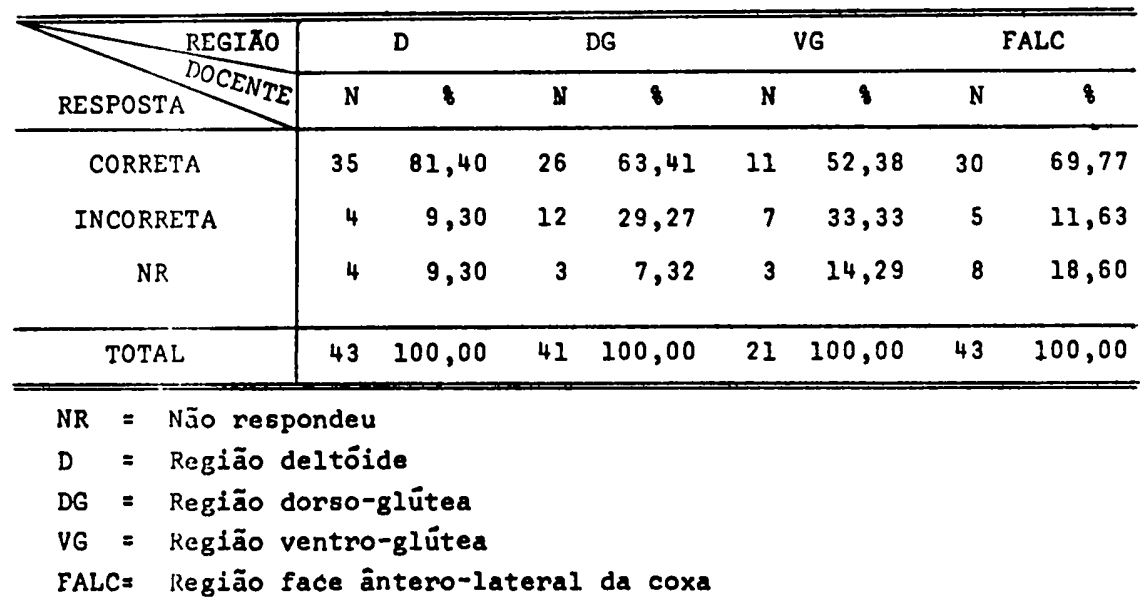

TABELA IV-b - Distribulção do nümero e porcentagem dos enfermeiros-hospi talares, segundo as respostas dadas em relação ao local de aplicação de injeção IM nas diferentes regiōes utilizadas.

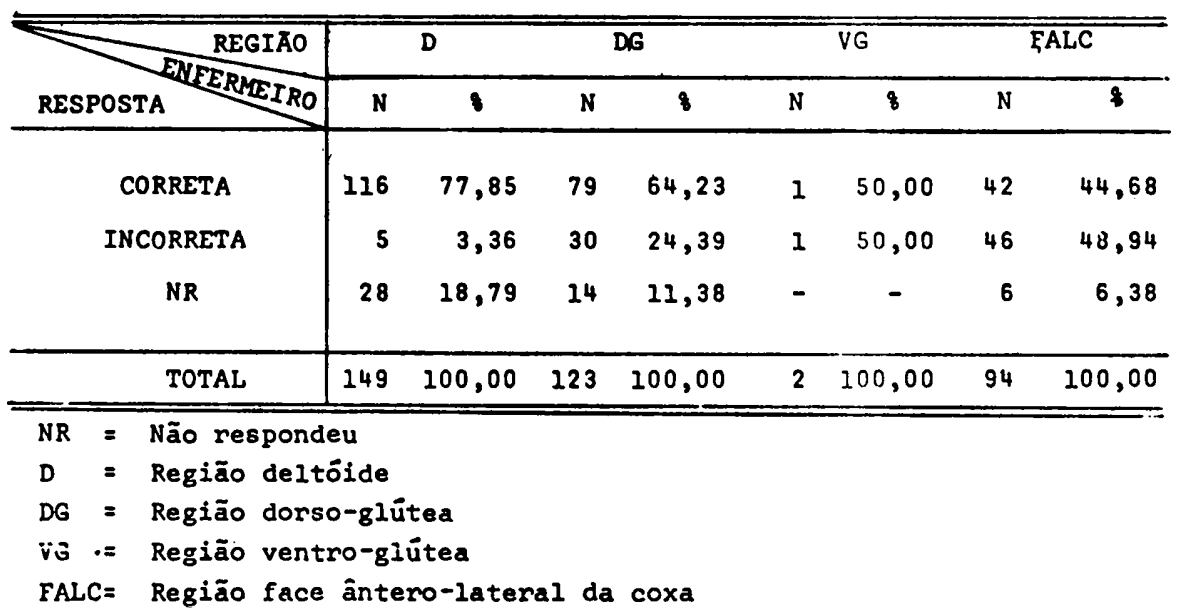


A punção da região $V G$, utilizada por quase metade $(43,75 \%)$ dos enfermeiros-docentes e unicamente por $1,29 \%$ dos enfermeiros-hospitalares (tabelas I-a e I-b), foi corretamente localizada por $11(52,38 \%-22,92 \%$ da população total) dos enfermeiros-docentes e por $1(50,00 \%-0,64 \%$ da população total) enfermeiro-hospitalar e incorretamente por $7(33,33 \%-14,58 \%$ da população total $)$ enfermeiros-docentes e $1(50,00 \%-0,64 \%$ da população total) enfermeiro-hospitalar; a pouca utilização desta região pelos enfermeiros em geral e a pobreza da bibliografia em português a respeito talvez sejam os responsáveis por tais erros de localização.

A punção na região $F A L C$, utilizada por quase todos os enfermeiros-docentes $(89,58 \%)$ e por aproximadamente $2 / 3(60,65 \%)$ dos enfermeiros-hospitalares (tabelas I-a e I-b), foi localizada com correção por pouco mais de $2 / 3(69,77 \%-62,50 \%$ da população total) dos enfermeiros-docentes e por quase a metade $(44,68 \%-26,92 \%$ da população total) dos enfermeiros-hospitalares, e incorretamente por $5(11,63 \%$ - $10,42 \%$ da população total ) e $46(48,94 \%$ $29,49 \%$ da população total), respectivamente. Como podemos observar, alguns enfermeiros-docentes e quase a metade dos enfermeiros-hospitalares não localizaram corretamente a zona de aplicação da injeção IM nesta região, dados estes que sugerem a necessidade de uma reavaliação de seus conhecimentos sobre essa região, pois as localizações consideradas como incorretas foram em local muito dorsal ou muito próximo à zona de flexão da coxa, podendo ocasionar lesão do nervo ciático, ou na face média anterior, possibilitando punctura acidental de importantes estruturas neuro-vasculares que se encontram ântero-medialmente ao fêmur.

Analisando ainda as tabelas IV-a e IV-b, observamos que um número considerável de enfermeiros-docentes e enfermeiros-hospitalares deixou de responder à questão sobre a localização da punção da injeção, num total de 18 (12,33\%) enfermeiros-docentes e 48 (13,04\%) enfermeiros-hospitalares. Tentando encontrar uma justificativa para tal abstenção de resposta, consultamos a parte de "observações pessoais" do questionário, onde encontramos algumas referências à dificuldade de compreensão dos gráficos apresentados para a localização da injeção. Revendo a bibliografia, verificamos que os autores que apresentam esquemas indicando o local exato desta aplicação, utilizam gráficos semelhantes ao nosso, o qual foi adaptado dos apresentados por HOCHSTETTER (3), HORTA \& TEIXEIRA (6), WYETH LAB (2) e SUT- 
TON (9). Talvez a insegurança tenha sido o verdadeiro motivo da ausência dessas respostas.

\section{QUANTO Ȧ DIFERENCIAÇÃO NA ESCOLHA DA REGIÃO DE APLICAÇÃO DE INJEÇÃO IM DE ACORDO COM O SEXO E A IDADE DO CLIENTE}

Em algumas ocasiões observamos, em hospitais, centros de saúde e principalmente farmácias, certa diferenciação na escolha da região para aplicação de injeção $\mathrm{IM}$ de acordo com o sexo do cliente; para os do sexo masculino havia preferências pela região $\mathrm{D}$ e para $o$ feminino a região DG. As questões 5 e 6 do questionário foram elaboradas com $o$ intuito de verificar se os enfermeiros de nossa população levavam em consideração este parâmetro na escolha da região para aplicação de injeção IM.

Pelas respostas dadas verificamos que somente $1(2,08 \%)$ enfermeiro-docente e $14(8,97 \%)$ enfermeiros-hospitalares escolhem regiões diferentes conforme o sexo do cliente. $O$ enfermeiro-docente deu preferência à região $\mathrm{D}$ em caso de cliente do sexo masculino e região DG para os do sexo feminino.

Na tabela V-b foram colocados o número e a porcentagem dos enfermeiros-hospitalares que, de acordo com o sexo do cliente, dão preferência a determinada região para aplicação de injeção IM.

Como podemos observar pela tabela V-b, a região $D$ também foi a preferida pelos enfermeiros-hospitalares para os clientes do sexo masculino $(7,05 \%)$ e as regiões DG $(2,56 \%)$, FALC $(1,92 \%)$ e VG $(0,64 \%)$ para as do sexo feminino. Um enfermeiro observou que também "dependia do sexo de quem aplica". Essa diferenciação talvez possa ser explicada pelo tradicionalismo e por fatores culturais que levam as pessoas a evitarem expor certas partes do corpo, principalmente ao sexo oposto (a grande maioria de nossa população foi de mulheres). Acreditamos que a atitude profissional no desenvolvimento de qualquer procedimento ajude a deixar mais à vontade tanto o paciente como o aplicador. Nenhum dos autores consultados estabelece distinção por sexo para aplicação das injeções e anatomicamente também não existe razão para isto. 
HORTA \& TEIXEIRA (6), analisando a escolha da região para aplicação de injeção IM, referem que um dos parâmetros que devem ser levados em consideração é o grupo etário a que pertence o cliente.

Nas tabelas VI-a e VI-b foram colocados os números e a porcentagem dos enfermeiros-docentes e hospitalares que, de acordo com a idade do cliente, preferem determinada região para aplicação de injeção IM.

TABELA V-b - Distribuição do número e porcentagem dos 14 enfermeiros-hospitalares que, de acordo com o sexo do cliente, indicam ou aplicam a injeção IM em diferentes regiōes.

\begin{tabular}{l|lccc}
\hline SEXO DO & \multicolumn{1}{l}{ MASCULINO } & \multicolumn{2}{l}{ FEMININO } \\
\hline REGIAD & & & & \\
\hline D & $\mathrm{N}$ & $\% \mathrm{~T}^{*}$ & $\mathrm{~N}$ & $\% \mathrm{~T}^{*}$ \\
\hline VG & 11 & 7,05 & - & - \\
FALC & - & - & 4 & 2,56 \\
\hline
\end{tabular}

$$
\begin{aligned}
& \text { * = Porcentagem tirada em relação à população total } \\
& \text { D = Região deltóide } \\
& \text { DG = Região dorso-glútea } \\
& \text { VG = Região ventro-glútea } \\
& \text { FALC = Região face ântero-lateral da coxa }
\end{aligned}
$$


TABELA VI-a - Distribuição do número e porcentagem dos enfermeiros-docentes que, de acordo com a idade do cliente, fazem ou não diferenciação quanto ao local de aplicação de injeção IM.

\begin{tabular}{c|cc}
\hline & \multicolumn{2}{|c}{ ENFERMEIRO-DOCENTE } \\
DIFERENCIAÇÃO & $\mathrm{N}$ & $\%$ \\
\hline SIM & 40 & 83,33 \\
NAOO & 8 & 16,67 \\
\hline TOTAL & 48 & 100,00 \\
\hline
\end{tabular}

TABELA VI-b - Distribuição do número e porcentagem dos enfermeiros-hospitalares que, de acordo com a idade do cliente, fazem ou não diferenciação quanto ao local de aplicação de injeção IM.

\begin{tabular}{l|cc}
\hline \multirow{2}{*}{ DIFERENCIAÇAO } & \multicolumn{2}{|c}{ ENFERMEIRO-HOSPITALAR } \\
& $\mathrm{N}$ & $\%$ \\
\hline SIM & 129 & 82,69 \\
NÃO & 26 & 16,67 \\
NR & 1 & 0,64 \\
\hline TOTAL & 156 & 100,00 \\
\hline \multicolumn{2}{l}{ NR = Não respondeu }
\end{tabular}


Os dados das tabelas VI-a e VI-b mostram que $83,33 \%$ dos enfermeiros-docentes e $82,69 \%$ dos enfermeiros-hospitalares consideram a idade do paciente importante para a escolha da região a ser utilizada. Dentro do nosso critério para a classificação dos grupos etários, fizemos uma reclassificação, no grupo dos lactentes, para "lactentes até 1 ano" e "lactentes de 1 a 2 anos", pois houve uma diferença muito grande na frequêencia das indicações para estas duas faixas de idade. As faixas etárias e as regiões escolhidas encontram-se nas tabelas VII-a e VII-b.

Analisando esses dados, verificamos que a indicação da região $D$ em ordem decrescente de preferência foi:

1 - enfermeiros-docentes: adulto; adolescente e velho; escolar e pré-escolar; lactente de 1 a 2 anos e lactente (até 1 ano) e neo-natal;

2 - enfermeiros-hospitalares: adulto; púbere e pós-púbere; pré-púbere; velho; escolar; pré-escolar e lactente (até 2 anos) e neo-natal.

A indicação desta região de preferência para os adultos concorda com a bibliografia consultada, pois devido às suas várias desvantagens e conseqüentes contra-indicações, quando houver sua utilização ela deverá ser para indivíduos com bom desenvolvimento muscular, a fim de ter-se o maior volume possível de massa do músculo deltóide. Pelas mesmas razões ela não é aconselhada para os velhos $(41,67 \%$ dos enfermeiros-docentes a indicaram) nem para as crianças pequenas (houve sua indicação numa variação de $5,77 \%$ a $25,00 \%$ ) e tampouco para recém-nascidos (houve cerca de $4 \%$ de enfermeiros-docentes e enfermeiros-hospitalares que a indicaram).

A indicação da regiâo $D G$, em ordem de preferência foi:

1 - enfermeiros-docentes: adulto; velho, adolescente, escolar e pré-escolar; lactente de 1 a 2 anos; lactente (até 1 ano) e neo-natal;

2 - enfermeiros-hospitalares: adulto; escolar, pré-escolar e lactente de 1 a 2 anos; velho, adolescente, lactente (até 1 ano) e neo-natal.

Apesar de ser esta região aconselhada por alguns autores indiferentemente da idade do cliente, concordamos com os enfermeiros- 


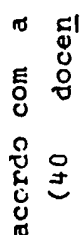

ข

a

is

品

ए

है

4.

ณ

ह

\%

出

o

ถิ

-

\&

点

옹

웅 -

'곡

है

出

告

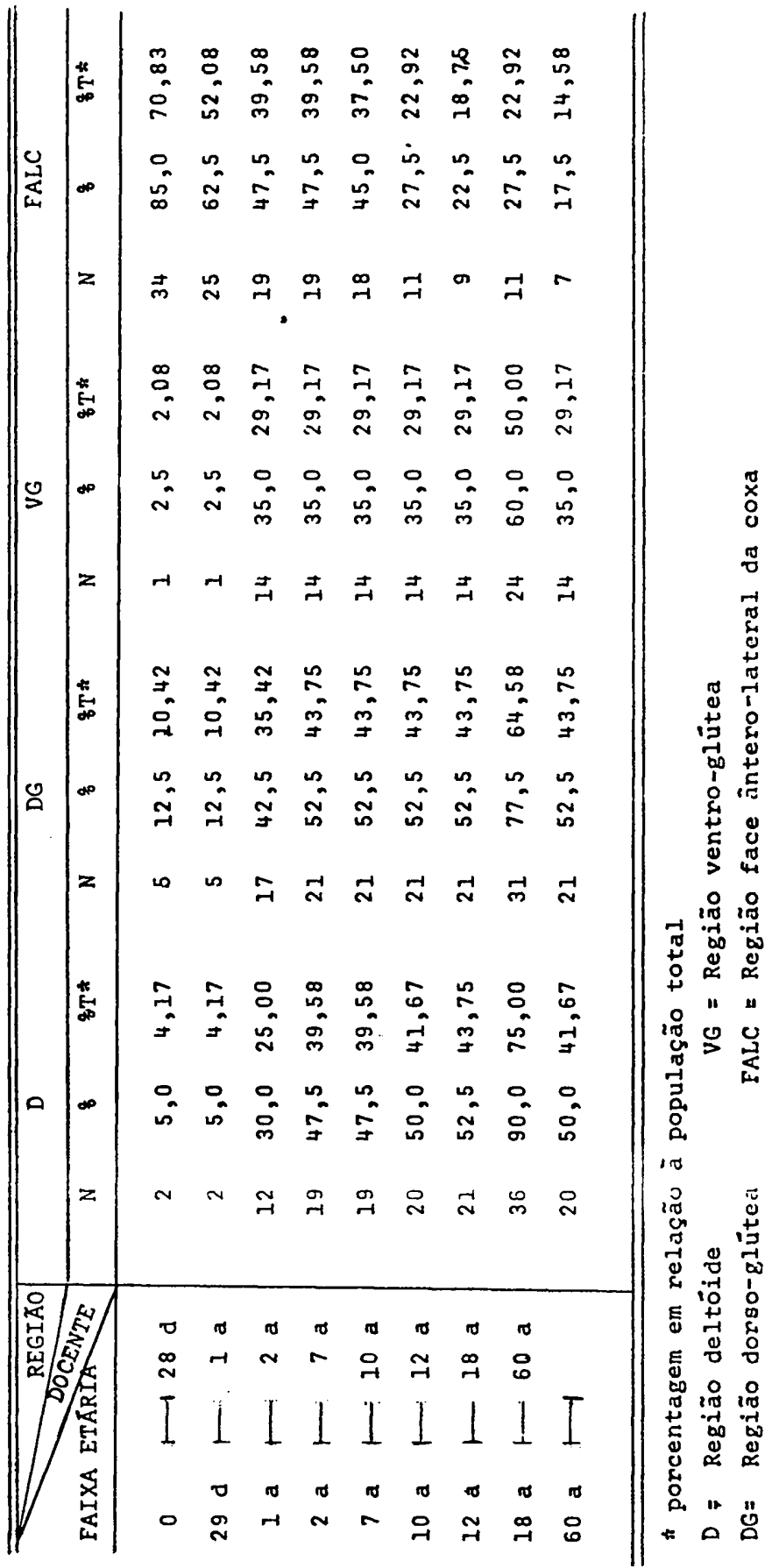




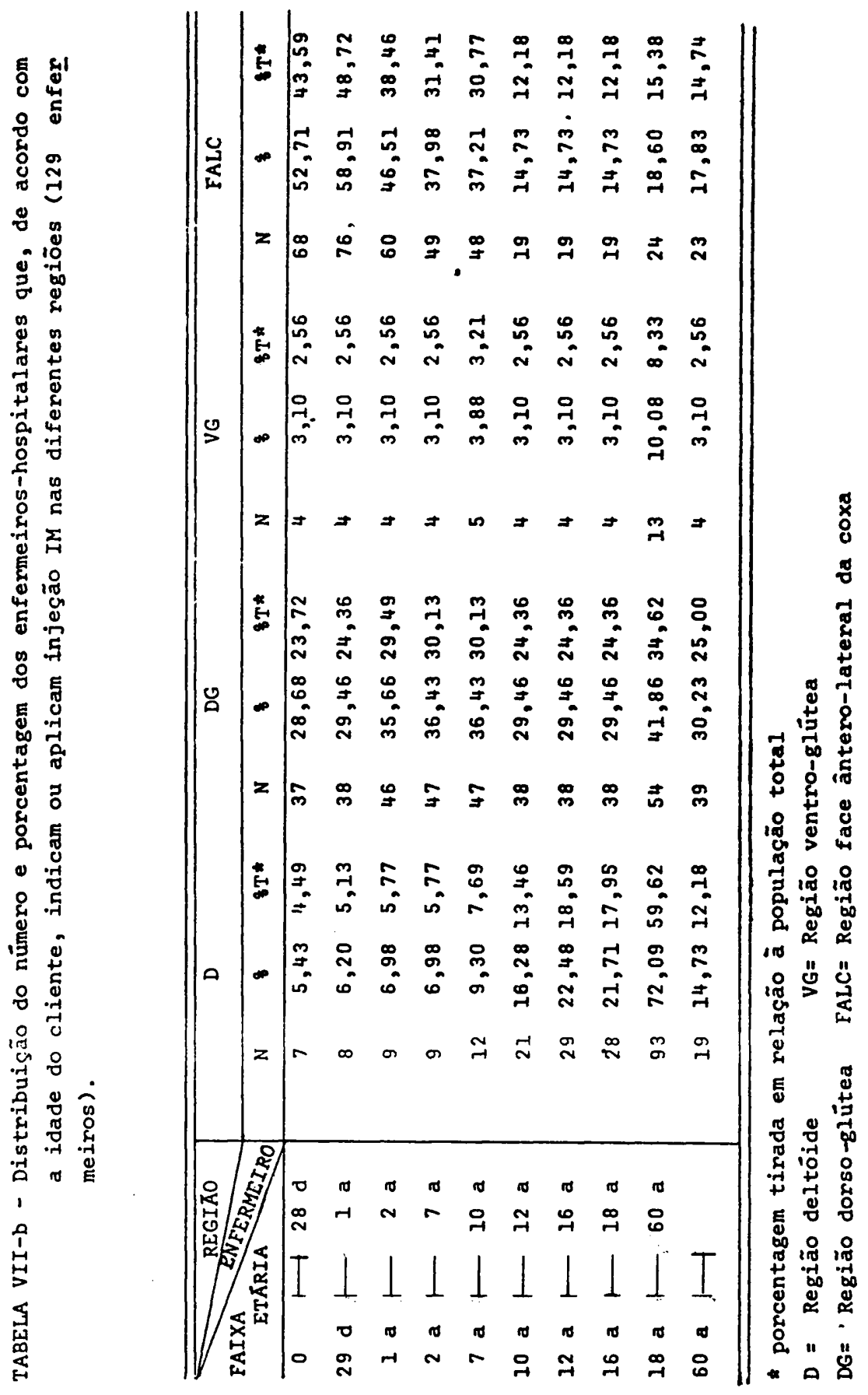


docentes e hospitalares que não utilizam esta região para crianças de 0 - 2 anos, pois ela deve ser evitada para crianças que não aceitam bem a injeção, uma vez que ficarão tensas, contraídas e não se conseguirá colocá-las em decúbito ventral apropriado, situações estas que interferem na aplicação segura da injeção nesta região e também para crianças que não estejam deambulando por já um ano (geralmente aos 2 anos de idade).

Analisando os dados das tabelas VII-a e VII-b, verificamos que esta região foi indicada para esta faixa etária de 0 a 2 anos com frequiência relativamente alta, pois atingiu a porcentagem de $10,42 \%$ ( 0 - 28 dias e lactente até 1 ano) e de $35,42 \%$ (lactente de 1 a 2 anos) dos enfermeiros-docentes e de $23,72 \%$ ( $0-28$ dias), $24,36 \%$ (lactente até 1 ano) e $29,49 \%$ (lactente de 1 a 2 anos) dos enfermeiros-hospitalares. Nota-se também que para os enfermeiros-docentes houve um aumento de frequêencia para a faixa etária de maiores de 2 anos, ou seja, para o grupo etário onde a criança já está deambulando por um ano ou mais. A não utilização dessa região para pacientes idosos pode ser devida ao fato de que para tal faixa etária deve-se avaliar bem a massa muscular, geralmente atrofiada, para se ter segurança de que o medicamento será depositado em tecido muscular e não no subcutâneo ou fora dos limites anatômicos aconselhados.

A indicação da região $V G$, em ordem de preferência, foi:

1 - enfermeiros-docentes: adulto; lactente de 1 a 2 anos, pré-escolar, escolar, adolescente e velho; lactente (até 1 ano) e neo-natal;

2 - enfermeiros-hospitalares: adulto; escolar; os demais.

Ainda que esta região seja aconselhada por vários autores que a consideram como realmente segura, devido à ausência de qualquer vaso ou nervo importantes e à pequena espessura de seu tecido subcutâneo (a única desvantagem encontrada na bibliografia consultada é a apreensão do cliente pelo fato de não conhecer esta região ou ver a sua administração), a nossa população em estudo manifestou bastantes reservas à sua indicação.

Os diferentes autores indicam a utilização dessa região em qualquer faixa etária, sendo inclusive mencionada, como uma de suas vantagens, a sua utilização para crianças e indivíduos idosos, magros e emaciados. Sua principal vantagem para este grupo etário é a 
precisão da localização e o fato de poder ser utilizada em qualquer decúbito.

A própria insegurança conseqüente ao menor conhecimento de tal região e à sua menor utilização na prática diária talvez tenha levado os enfermeiros-docentes e principalmente os enfermeiroshospitalares a indicá-la com menor frequêencia para as crianças, clientes que podem provocar um maior sentimento de insegurança no seu cuidado por parte de enfermeiros não especializados em pediatria.

cia, foi:

A indicação da região $F A L C$, em ordem de preferên-

1 - enfermeiros-docentes: neo-natal; lactentes (até 1 ano); lactentes de 1 a 2 anos; pré-escolar e escolar; adolescentes e adultos; velhos;

2 - enfermeiros-hospitalares: lactente (até 1 ano); neonatal; lactente de 1 a 2 anos; pré-escolar e escolar; adulto e velho; adolescente.

A maior indicação de tal região na infância é concordante com as publicações a seu respeito.

Consultando os dados relativos à sua indicação para a faixa neo-natal, verificamos que $70,83 \%$ dos enfermeiros-docentes e $43,59 \%$ dos enfermeiros-hospitalares a indicaram para este grupo. De acordo com os estudos de alguns autores, pode haver contratura do quadríceps femoral e lesão da artéria femoral após sua utilização em crianças. Com base nesses estudos aconselhamos a sua não utilização para o grupo etário de $0-1$ ano, no caso de grande número de aplicação e técnica diferente da mencionada por TALBERT (10) (agulha $2,5 \mathrm{~cm}$ e angulação de $45^{\circ}$ ).

Sua indicação para o grupo etário dos adolescentes e adultos foi menor do que para a infância. Isto se justifica pelo fato de ser bem mais dolorosa devido à freqüente lesão do nervo cutâneo femoral.

\section{QUANTO AO CONHECIMENTO DE CONTRA-INDICAÇŐES A UTILIZAÇÃO DE CADA UMA DAS REGIOES DE APLICAÇÃO DE INJEÇÃO IM}

Cada uma das regiões de aplicação de injeção IM tem suas vantagens e desvantagens, já bastante discutidas nos itens anterio- 
TABELA VIII-a - Distribuição do número e porcentagem dos enfermeiros-docentes quanto ao conhecimento de contra-indicações ao uso de alguma região para aplicação de injeção IM.

\begin{tabular}{c|cc}
\hline $\begin{array}{c}\text { CONHECIMENTO } \\
\text { DE }\end{array}$ & \multicolumn{2}{|c}{ ENFERMEIRO-DOCENTE } \\
CONTRA-INDICAÇÃO & $\mathrm{N}$ & $\%$ \\
\hline SIM & 24 & 50,00 \\
NÃO & 23 & 47,92 \\
NR & 1 & 2,08 \\
\hline TOTAL & 48 & 100,00 \\
\hline
\end{tabular}

$\mathrm{NR}=$ Não respondeu

TABELA VIII-b - Distribuição do número e porcentagem dos enfermeiros-hospitalares quanto ao conhecimento de contra-indicações ao uso das regiões de aplicação de injeção IM.

\begin{tabular}{c|cc}
\hline $\begin{array}{c}\text { CONHECIMENTO } \\
\text { DE } \\
\text { CONTRA-INDICAÇÃO }\end{array}$ & N & $\%$ \\
\hline SIM & 53 & 33,97 \\
NÃO & 95 & 60,90 \\
NR & 8 & 5,13 \\
\hline TOTAL & 156 & 100,00 \\
\hline
\end{tabular}

$\mathrm{NR}=$ Não respondeu 
res. Tanto as vantagens quanto as desvantagens devem ser levadas em consideração na seleção da região mais adequada para cada cliente.

Nas tabelas VIII-a e VIII-b foram colocados o número e a porcentagem dos enfermeiros-docentes e hospitalares que mencionam conhecer contra-indicações à utilização de algumas das regiões para aplicação de injeção IM.

Os dados das tabelas VIII-a e VIII-b mostram que somente a metade dos enfermeiros-docentes $(50,00 \%)$ e unicamente $1 / 3$ dos enfermeiros-hospitalares $(33,97 \%)$ mencionaram conhecer contraindicações às diferentes regiões. Nos Quadros 1-a e 1-b (Anexo 2) encontra-se a relação de todas as contra-indicações indicadas pelos enfermeiros-docentes e enfermeiros-hospitalares.

Nas tabelas IX-a e IX-b encontram-se as frequiências com que ambos os grupos de enfermeiros relataram contra-indicações a cada uma das regiões e as frequiências com que estas foram gerais a todas as regiões ou específicas a cada uma delas e concordantes com as mencionadas pelos estudiosos do assunto - critério de avaliação das contraindicações (item 4.4.1).

Analisando os dados referentes à região $D$, verificamos que esta, ainda que com freqüência bastante baixa, foi a mais citada, tanto pelos enfermeiros-docentes $(22,92 \%$ da população total), como pelos enfermeiros-hospitalares $(12,82 \%$ da população total); as contraindicações específicas e concordantes com os autores consultados foram em número ainda menor, pois somente 5 dos 11 enfermeiros-docentes $(10,42 \%$ da população total) e 17 dos 20 enfermeiros-hospitalares ( $10,9 \%$ da população total) as mencionaram e mesmo estes deixaram de citar algumas; as citadas pelos enfermeiros-docentes foram: volume grande de solução (1), pequeno volume de massa muscular (3), localização de importantes nervos e vasos (1), dor e sensibiliade local grandes (1); os enfermeiros-hospitalares indicaram: injeções consecutivas (2), volume grande de solução (7), substâncias irritantes (4), pequeno volume da massa muscular (10), localização de importantes nervos e vasos (1).

O músculo deltóide, pelo seu pequeno volume muscular, realmente não pode receber grande quantidade de solução e não pode ser utilizado para injeções consecutivas. Graças, também, a essa pequena extensão muscular, somente podem ser injetadas substâncias não irritantes. 


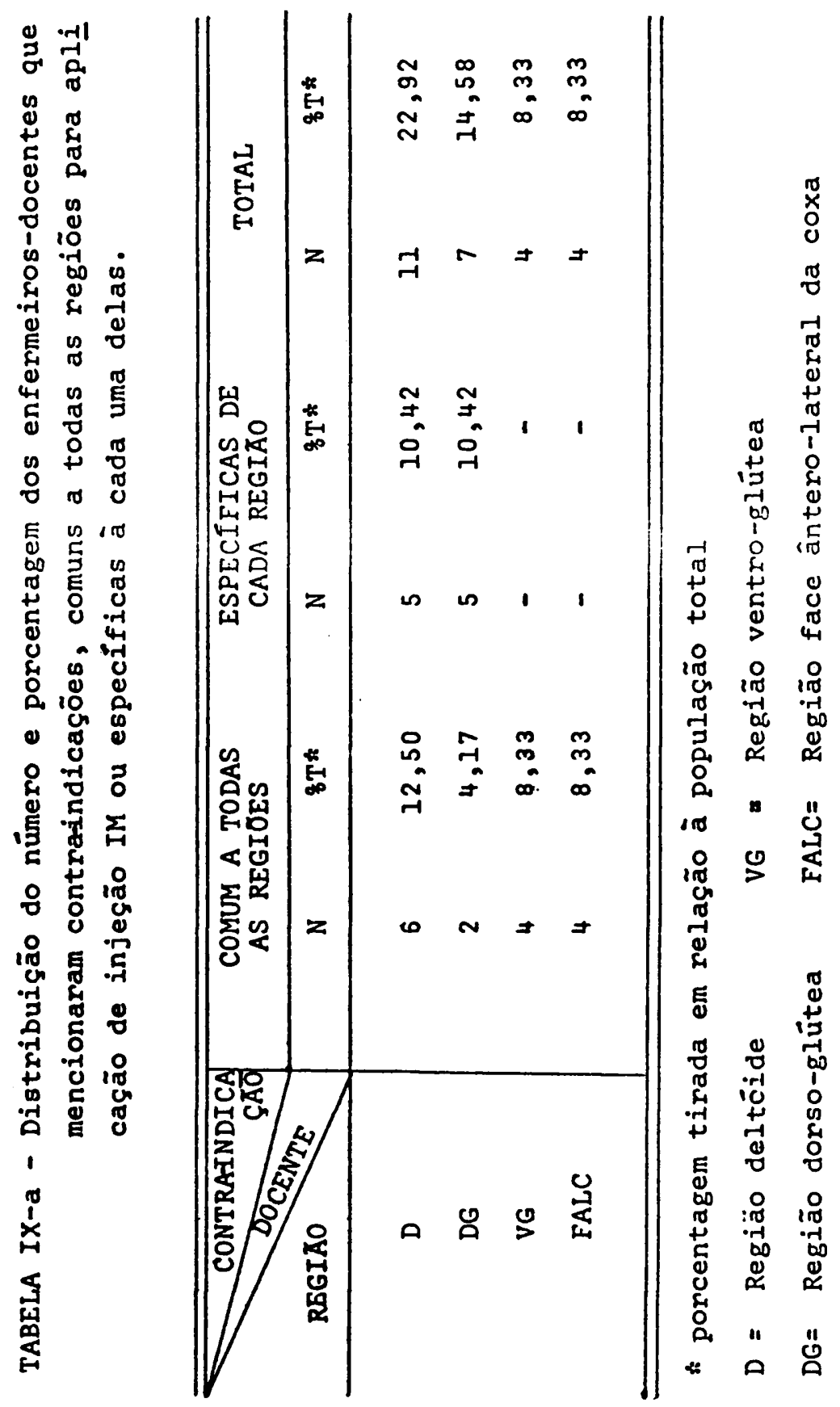




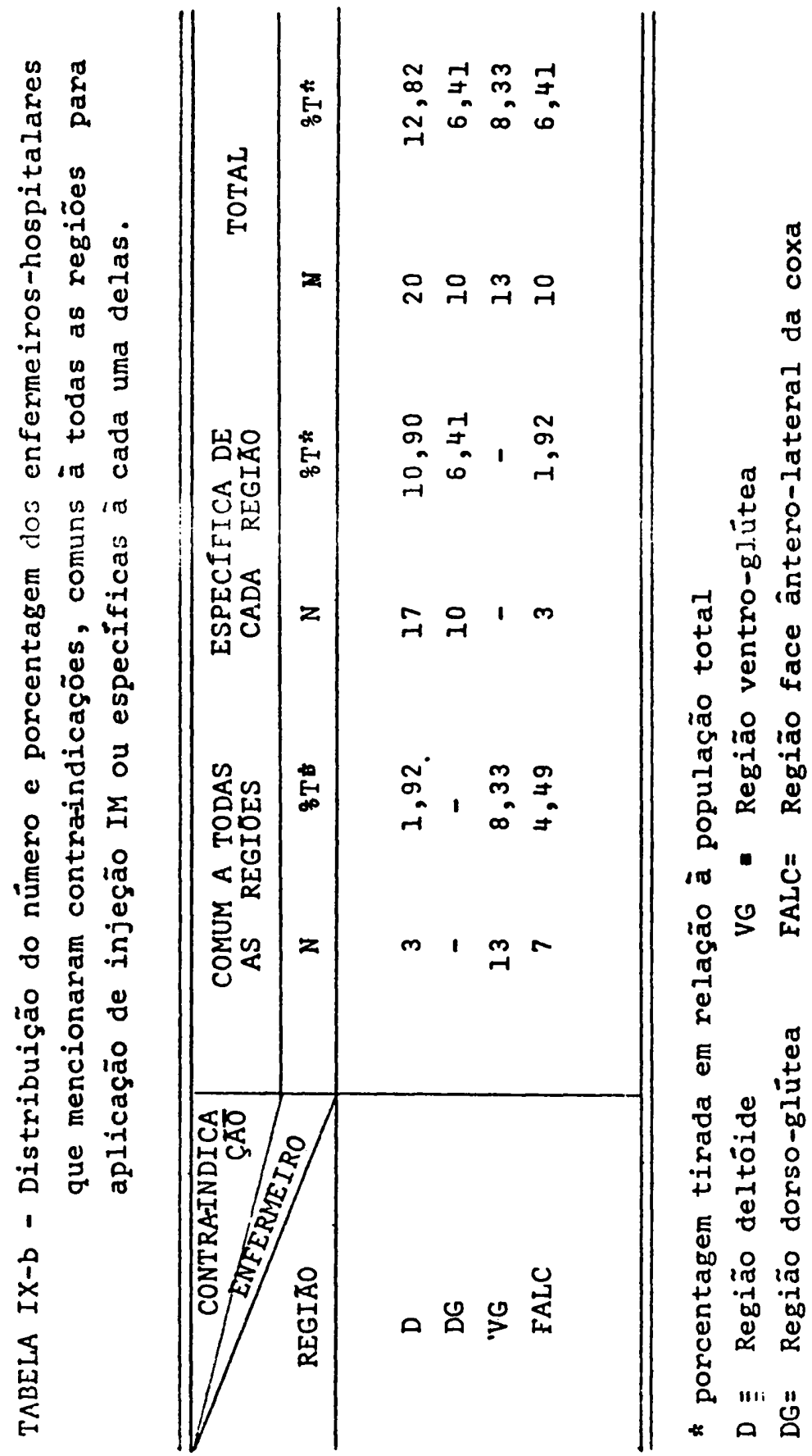


Com relação à localização de importantes vasos e nervos, ramos do feixe vásculo-nervoso podem estar nessa região, em casos de variações anatômicas individuais, existindo o perigo de lesão do nervo radial, que se encontra na borda látero-inferior do deltóide e de se atingir a artéria umeral, tanto por punção direta dessas estruturas como por difusão da droga e consequientemente irritação do epineurônio do nervo radial, chegando até a provocar lesões dos nervos mediano e ulnar.

A sensibilidade maior nessa área, única contra-indicação não mencionada por nenhum dos enfermeiros-docentes e enfermeiroshospitalares, é considerada como um dos motivos que levam à contraindicação da sua utilização. As demais contra-indicações mencionadas (Quadros 1-a e 1-b) são válidas, mas são comuns a qualquer região. Procurando verificar se as mencionadas eram respeitadas, consultamos os dados tabulados de cada elemento da população referentes às regiões utilizadas e à correção da localização da punção e verificamos que elas são respeitadas e as localizações foram corretas, em ambos os grupos da população.

Poderíamos argumentar que o alto índice da utilização de tal região $(89,58 \%$ dos enfermeiros-docentes e $96,18 \%$ dos enfermeiroshospitalares (tabelas I-a e I-b) talvez seja devido a esse desconhecimento de suas reais contra-indicações.

Quanto à região $D G$, verifica-se que suas contra-indicações foram citadas também por poucos profissionais, $14,58 \%$ dos enfermeiros-docentes e $6,41 \%$ dos enfermeiros-hospitalares, sendo que 5 dos 7 enfermeiros-docentes $(10,42 \%$ da população total) e os 10 enfermeiroshospitalares $(6,41 \%$ da população total) fizeram menção a contra-indicações específicas e concordantes com os autores, mas também não citaram todas. Os enfermeiros-docentes mencionaram: lactente de 0 2 anos (2), indivíduos debilitados (1), localização do nervo ciático (3) e os enfermeiros-hospitalares indicaram: utilização do ângulo interno do quadrante superior externo (1), lactente de $0-2$ anos e indivíduos debilitados (1), localização do nervo ciático (4) e localização de importantes vasos (1).

A contra-indicação da utilização desta região para o grupo etário de $0-2$ anos, é concordante com vários autores que a contra-indicam para crianças nessa faixa etária, por ser extremamente pequena e composta primariamente de gordura; há somente um pequeno desenvolvimento da massa muscular e qualquer injeção ficará 
perigosamente perto do nervo ciático. Deve-se acrescentar que uma criança chorosa, esperneante e não cooperativa aumenta o perigo de se injetar dentro ou nas adjacências do nervo ciático, não só devido à área relativamente pequena nesses indivíduos, como também pela maior probabilidade de uma angulação inadequada da agulha. $O$ recém-nascido e o prematuro estão mais sujeitos à lesão ciática, pois a região é ainda menor em extensão e profundidade. Tal problema agrava-se mais, quando lembramos que os clientes de tal faixa etária não são capazes de indicarem qualquer sintoma específico, durante ou após a injeção, com conseqüente retardo do diagnóstico e da instalação de medidas terapêuticas, preventivas e curativas. Após a deambulação, já há suficiente desenvolvimento desses músculos para poder receber injeções. A não indicação dessa região para indivíduos debilitados justifica-se pelo fato de que seus músculos estão geralmente atrofiados, diminuindo, portanto, a área muscular em extensão e profundidade, bem como aumentando a proximidade do nervo ciático de seus limites anatômicos e conseqüente possibilidade de lesão acidental.

Com referência à contra-indicação da região DG, devido ̀̀ localização de importantes vasos e do nervo ciático nesta região, verifica-se ser concordante com vários autores que realizaram investigações e estudo a esse respeito. A contra-indicação dessa região não se deve unicamente à localização em si de grandes vasos e nervos, mas também à possíveis variações morfológicas individuais, descritas em crianças e em adultos. As várias investigações clínicas e experimentas demonstraram que as lesões ciáticas não são somente consequientes a injeções intra-neurais mas também à localização paraneural do depósito medicamentoso; são citados também espasmos, tromboses e embolias dos vasos de sustentação do nervo.

A contra-indicação da utilização do ângulo interno do quadrante superior externo é confirmada por vários autores, devendo-se isto ao fato de que o nervo ciático, em alguns indivíduos, ainda pode ser encontrado em tal área da região DG.

Como se pode observar, a posição do cliente, a angulação e o tamanho da agulha não foram referidos nenhuma vez, fatores esses bastante relevantes para a prevenção de complicações.

O paciente não deve ficar em decúbito lateral, pois essa posição distorce os contornos anatômicos da região, resultando uma 
aplicação mais abaixo do que deveria ser. A administração de injeção com o indivíduo de pé é contra-indicada, pois os músculos ficarão contraídos, dificultando a introdução da agulha e do líquido e facilitando a volta da solução pelo trajeto da agulha e para o tecido subcutâneo, além de ser extremamente dolorosa, pois a inervação sensorial destes músculos consiste predominantemente de fibras pressosensitivas.

Estudos experimentais em cadáveres demonstraram a necessidade de ser a injeção aplicada com a agulha em angulação perpendicular à superfície onde o cliente está deitado, a fim de que lesões do nervo ciático sejam prevenidas.

O comprimento da agulha deve ser tal, que não permita deposição inadequada do medicamento no tecido subcutâneo, diminuindo a velocidade de absorção, interferindo no efeito terapêutico e provocando maior reação tissular às características irritantes do medicamento; isso levaria à formação de nódulos e abcessos estéreis. Além disso, a injeção no tecido subcutâneo é mais dolorosa devido à sensibilidade de sua inervação.

Uma das explicações para a omissão destas contra-indicações talvez possa ser a de que em nossa bibliografia nacional não haja menção a esses cuidados.

As outras contra-indicações mencionadas (Quadro 1) foram válidas, mas não específicas dessa região, merecendo ser comentada a contra-indicação "grande número de aplicações", citada por um enfermeiro, pois nos parece que o número consecutivo de injeções nessa região deve ser encarado não como uma contra-indicação, mas sim como "problema de enfermagem", definido por HORTA (5), para o qual o rodízio das regiões e dos locais de aplicação seria uma das soluções a ser incluída no plano de cuidado diário do paciente. $\mathrm{Na}$ análise relativa ao respeito às contra-indicações mencionadas, verificamos que um enfermeiro-hospitalar que contra-indicou a utilização de tal região para crianças e pacientes magros, localizou-a corretamente, mas a utiliza para "qualquer idade", e outro, que a utiliza também para qualquer idade e a contra-indicou pela presença do nervo ciático, a localizou incorretamente no quadrante inferior interno.

Com relação à região $V G$, citada por $8,33 \%$ dos enfermeiros-docentes e por também $8,33 \%$ dos enfermeiros-hospitalares, as 
contra-indicações levantadas foram gerais para todas as regiões ou foram discordantes dos autores, pois a única que estes mencionam é a angústia ou ansiedade do paciente pela utilização de uma região até aquele momento desconhecida ou devido ao fato de poder ele (paciente) vê-la, pois é suficientemente ventral para isto acontecer. Tal fato não foi mencionado por ninguém. Como contra-indicações a essa região (Quadros I-a e I-b) foram citadas contra-indicações comuns a qualquer região e outras que, fundamentadas nos estudos anatômicos anteriormente citados, consideramos não procedentes. São elas: localização do nervo ciático e outros nervos e vasos importantes, proximidade de alças intestinais e articulação coxo-femural. As contra-indicações de sua utilização para crianças, indivíduos caquéticos e excessivamente magros também não são procedentes, pois essas são características individuais para as quais tal região é justamente vantajosa; no caso da sua contra-indicação para a aplicação de vacinas, ainda que não tenhamos encontrado nenhuma referência bibliográfica a esse respeito, cremos mesmo dever ser ela aconselhada pois o grupo etário que com maior frequiência recebe imunizações é o de lactentes e crianças, para os quais há total indicação e segurança na sua utilização, conforme os vários estudos já descritos. E necessário ressaltar que somente um (1) dos 21 enfermeiros-docentes que utilizam a região VG (tabela I-a) mencionou conhecer alguma contra-indicação (para criança) e nenhum dos dois enfermeiros-hospitalares que a utilizam relatou qualquer uma.

Para a região $F A L C$, citada por $8,33 \%$ dos enfermeirosdocentes e $6,41 \%$ dos enfermeiros-hospitalares, não houve nenhuma contra-indicação específica e concordante com os autores por parte dos docentes. Apenas 3 dos 10 enfermeiros-hospitalares (1,92\% da população total) citaram algumas: volume grande de solução (1) e região dolorosa (2).

Realmente grande volume de soluções é contra-indicado principalmente para crianças, pois a expansão muscular é limitada por fascias inelásticas; a maior sensação dolorosa na utilização desta região é explicada pela lesão acidental do nervo femoral cutâneo.

Revendo as tabelas I-a e I-b observamos que tal região foi mencionada como sendo utilizada por quase a totalidade dos enfermeirosdocentes $(89,58 \%)$ e por $60,65 \%$ dos enfermeiros-hospitalares. Cremos que isto agrava tal situação de desconhecimento das suas contra- 
indicações; o não respeito a elas, tais como injeções consecutivas, agulha de comprimento outro que $2,5 \mathrm{~cm}$ e angulação não oblíqua ao eixo longitudinal horizontal da perna poderão ocasionar fibrose local, lesão da artéria femoral e do nervo femoral, respectivamente.

Do mesmo modo que a região DG, também a pobreza da bibliografia nacional a respeito das contra-indicações, principalmente dos problemas relativos à agulha, talvez seja a responsável por esse insuficiente conhecimento das contra-indicações específicas dessa região.

Entre as outras contra-indicações citadas (Quadros 1-a e 1-b), encontramos algumas comuns a qualquer região e duas que merecem uma análise mais detalhada; uma delas é a contra-indicação para "criança". De acordo com o critério de MARCONDES (7), por nós adotado, ela pertenceria à faixa etária de 2 a 10 anos, não incluindo, entretanto, o recém-nascido (neo-natal), para o qual alguns autores realmente contra-indicam essa região; a outra é sua contra-indicação para o sexo masculino devido ao excesso de pelos. Poderíamos argumentar que nem todos os homens possuem essa grande quantidade de pelos e, caso ela realmente fosse excessiva, ainda haveria a possibilidade de fazermos a tricotomia local, após orientação e consentimento do paciente, a fim de diminuirmos tal inconveniência.

Como todas as contra-indicações citadas não disseram respeito à localização da punção, não fizemos a análise respectiva.

\section{QUANTO AO CONHECIMENTO DE COMPLICAÇŐES NA UTILIZAÇĀO DE CADA UMA DAS REGIOESS DE APLICAÇĀO DE INJEÇÃO IM}

O conhecimento das possíveis complicações consequientes à aplicação de injeção IM é importante, tanto em nível preventivo como em nível curativo, pois se forem levadas em consideração na seleção da região mais adequada para cada cliente, haverá menor probabilidade de que ocorram e, caso não tenha sido possível preveni-las, o reconhecimento de seus sinais e sintomas mais precoces possibilitará o pronto encaminhamento do paciente para a assistência médica. $O$ diagnóstico precoce e a imediata instalação de medidas curativas diminuirão as possibilidades de seqüelas irreparáveis.

Nas tabelas X-a e X-b foram colocados os números e as porcentagens dos enfermeiros-docentes e hospitalares que mencionaram 
conhecer complicações conseqüentes à utilização de algumas das regiões para aplicação de injeção IM.

Os dados das tabelas X-a e X-b mostram que só cerca de $1 / 3$ dos enfermeiros-docentes $(31,25 \%)$ e unicamente $1 / 4$ dos enfermeiros-hospitalares $(25,64 \%)$ mencionaram conhecer complicações conseqüentes à utilização das regiões indicadas para administração de injeção IM. Nos quadros 2-a e 2-b (Anexo 3) encontra-se a relação de tondas as complicações relatadas pelos docentes e pelos enfermeiros.

Nas tabelas XI-a e XI-b estão as frequiências com que ambos os grupos de enfermeiros citaram complicações de cada uma das regiões e as frequiências com que estas foram gerais a todas as regiões ou específicas a cada uma delas e concordantes com as mencionadas pelos estudiosos do assunto (critério de avaliação das complicações, item 4.4.2).

Analisando os dados referentes à região $D$, verificamos que foi unicamente citada por $10,42 \%$ dos enfermeiros-docentes e por $7,05 \%$ dos enfermeiros-hospitalares, sendo que todas foram específicas a esta região e também concordantes com os autores consultados, ainda que nem todas as complicações tenham sido mencionadas. As citadas pelos enfermeiros-docentes foram: lesão de ramos do feixe vásculo-nervoso (1), lesão do nervo radial (3), lesão da artéria umeral (1); as mencionadas pelos enfermeiros-hospitalares foram: lesão dos ramos do feixe vásculo-nervoso (1), lesão do nervo radial (1), infiltrados e nódulos (9).

Realmente pode haver lesão tissular de ramos do feixe vásculo-nervoso (artérias e veias circunflexas ventral e dorsal e nervo circunflexo), em casos de variações anatômicas individuais e também por aplicação fora da área delimitada, com conseqüente alteração da nutrição e inervação do músculo deltóide. As lesões do nervo radial, geralmente conseqüentes à injeção administrada na face póstero-lateral do braço ou na borda inferior do deltóide, são graves podendo levar à neuropatia paralisante com envolvimento dos principais músculos do braço e antebraço. Esta mesma localização inadequada na região $D$ pode causar lesão da artéria umeral, complicação esta que levou alguns autores a indicá-la unicamente como última alternativa para o rodízio de injeções. As demais complicações conseqüentes à injeção na região $D$, tais como as lesões dos nervos escapular, axilar, mediano e ulnar e os infiltrados e nódulos não foram mencionados pela população em estudo. 
TABELA X-a - Distribuição do número e porcentagem dos enfermeiros-docentes quanto ao conhecimento de complicações à utilização das regiões de aplicação de injeção IM.

\begin{tabular}{c|cc}
\hline $\begin{array}{c}\text { CONHECIMENTO } \\
\text { DE }\end{array}$ & ENFERMEIRO-DOCENTE \\
COMPLICAÇĀO & 15 & $\%$ \\
\hline SIM & 32 & 31,25 \\
NÃO & 1 & 66,67 \\
NR & 48 & 2,08 \\
\hline TOTAL & 100,00 \\
\hline
\end{tabular}

NR = Não respondeu

TABELA X-b - Distribuição do número e porcentagem dos enfermeiros-hospitalares quanto ao conhecimento de complicações à utilização das regiões de aplicação de injeção IM.

\begin{tabular}{c|cc}
\hline $\begin{array}{c}\text { CONHECIMENTO } \\
\text { DE } \\
\text { COMPLICAÇAO }\end{array}$ & N & $\%$ \\
\hline SIM & 40 & 25,64 \\
NAO & 113 & 72,44 \\
NR & 3 & 1,92 \\
\hline TOTAL & 156 & 100,00 \\
\hline
\end{tabular}

NR = Não respondeu 


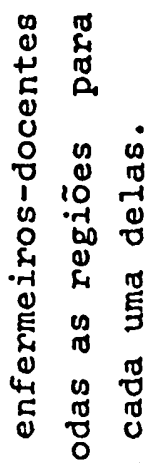

nt 8 a

- $\pi$

E 0

苾范

ᄃ 80

ơ is

용

- نั 0

- $0 \sum_{i}$

总沶监

'马 ญ

욤ำ

○

i⿱口

-

न

ऊ छ

点

I

苫

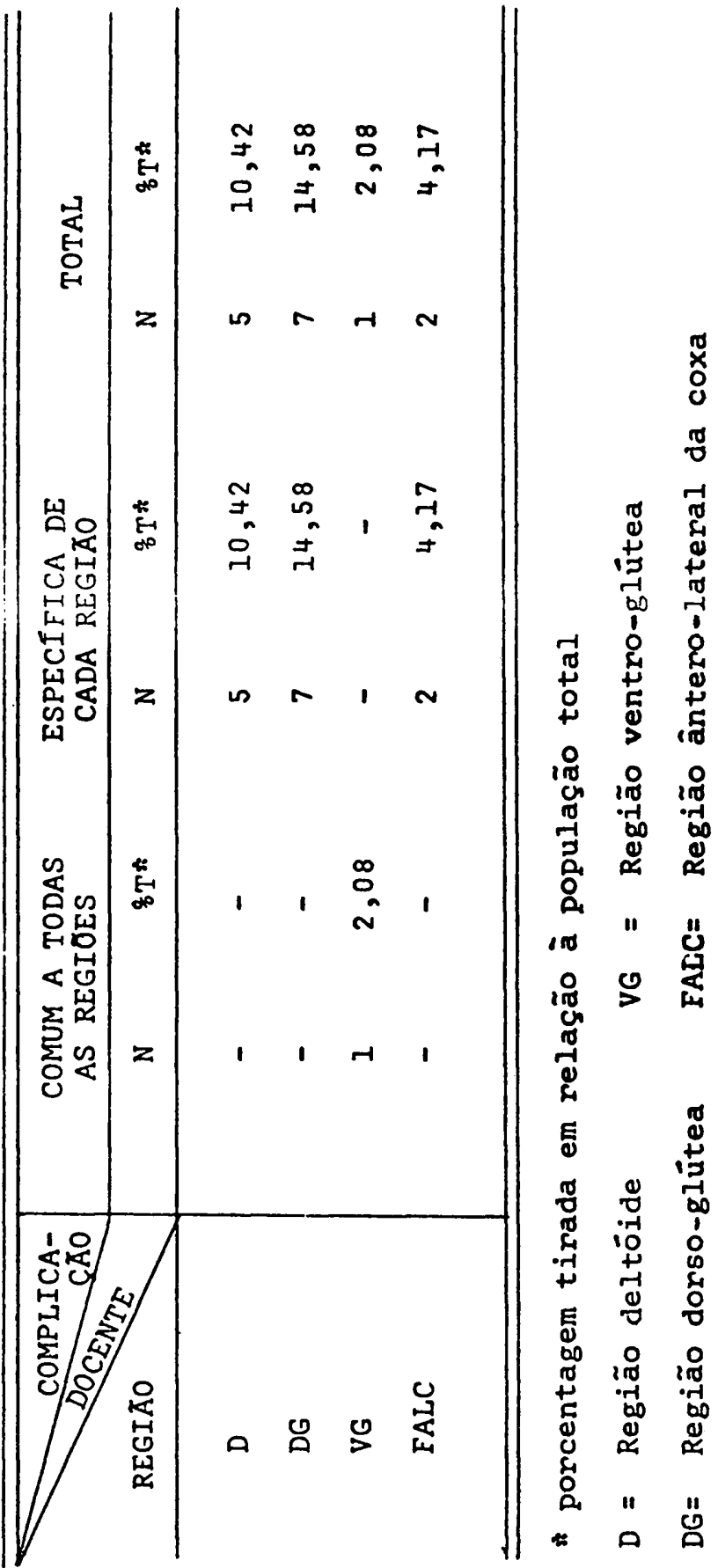




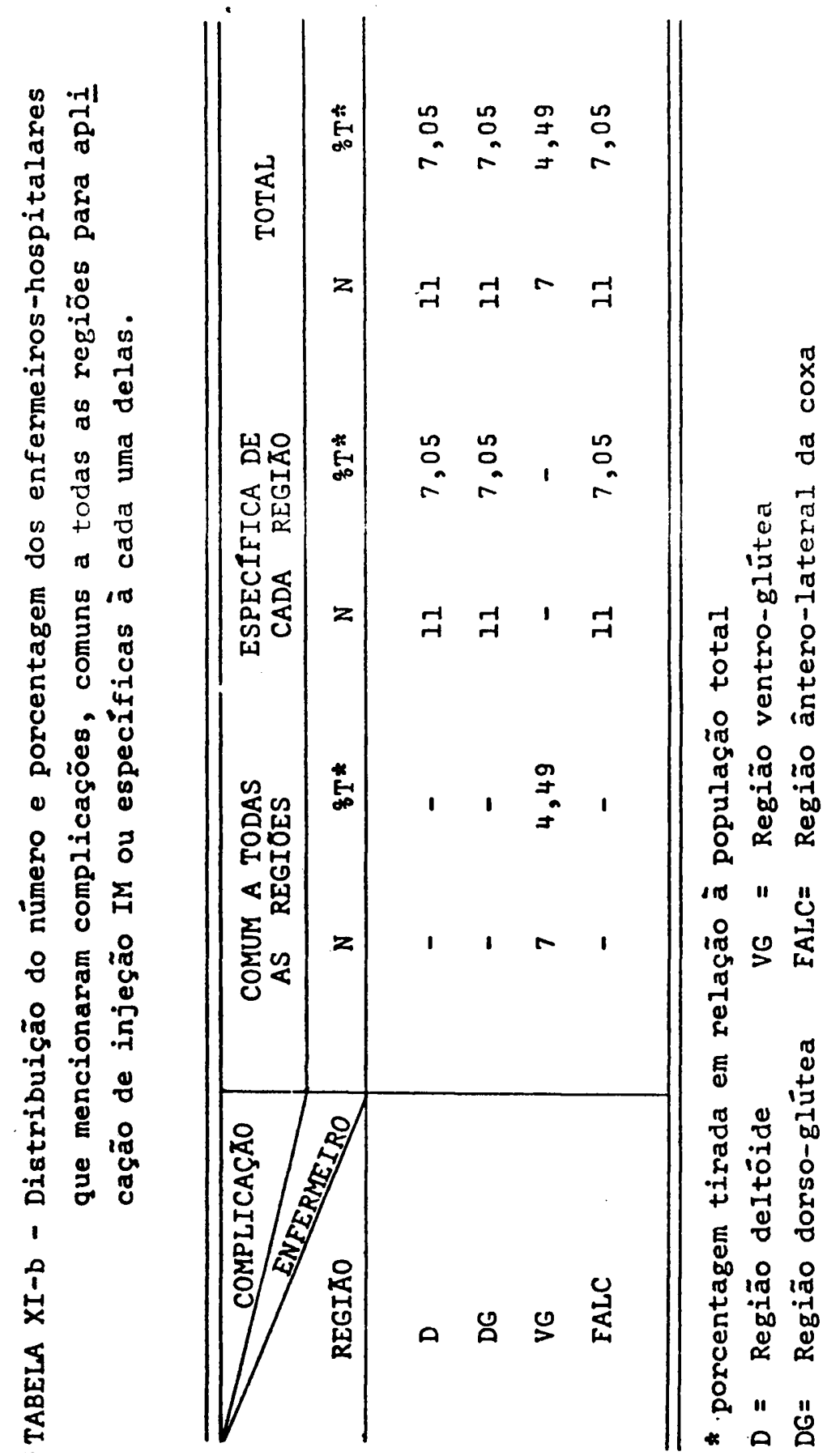


As primeiras geralmente são conseqüentes à má localização da punção e as últimas, sem dúvida, complicações bastante freqüentes na utilização dessa região, são resultantes da dificuldade da pequena massa muscular absorver adequadamente as substâncias injetadas e da alteração na estrutura histológica muscular conseqüente ao trauma mecânico e químico, provocado pela injeção.

Com relação à região $D G$, verifica-se que suas complicações foram mencionadas por bem poucos de nossa população: $14,58 \%$ dos enfermeiros-docentes e 7,05\% dos enfermeiros-hospitalares, sendo entretanto todas específicas a esta região e concordantes com as citadas pelos estudiosos do assunto, apesar de nem todas as complicações terem sido mencionadas. A citada pelos enfermeiros-docentes foi lesão do nervo ciático (7) e pelos enfermeiros-hospitalares foram: lesão do nervo ciático (10) e infiltrados subcutâneos (2).

Lesão do nervo ciático é realmente uma grave e bastante estudada complicação conseqüente à utilização da região DG. Estudos demonstraram que, com maior freqüência, e ocasionada por deposição para-neural do medicamento e, mais raramente, por injeção intra-neural; esse posicionamento indevido da solução injetada pode ser conseqüente à localização equívoca da punção da injeção, em virtude de não serem respeitados os limites anatômicos da região, pela angulação inadequada da agulha ou por localização anômala do nervo ciático, em casos de variações morfológicas individuais; também pode ser devido à sua utilização para clientes com pequeno desenvolvimento do tecido muscular glúteo, tais como crianças de $0-2$ anos, indivíduos debilitados e excessivamente magros. Lesões do nervo ciático podem provocar paralisia do músculo dorsiflexor do pé, com déficit sensorial e anidrose, quando unicamente sua ramificação for atingida, ou completa paralisia abaixo do joelho, quando ambas as ramificações forem envolvidas. Quando o paciente é criança, pode haver encurtamento do membro inferior e deformidade do pé.

Os infiltrados subcutâneos são complicações bastante freqüentes e podem ser explicados pela grande variabilidade da espessura do tecido subcutâneo e pela dificuldade em se estimá-lo pelo palpação, pois o panículo adiposo está firmemente aderido à fascia inferior por tecido conetivo. Isto pode levar o aplicador a uma escolha inadequada do comprimento da agulha e conseqüente deposição do medicamento no tecido subcutâneo, ao invés de no muscular; em caso de substâncias não 
lipossolúveis, as complicações agravam-se pois o medicamento além de agir como corpo estranho não será absorvido, interferindo no seu efeito terapêutico.

As demais complicações, tais como as lesões dos nervos glúteo superior e inferior, glúteo craneal, póstero femoral cutâneo e pudendo, embolia pulmonar, necrose da área glútea, gangrena de vísceras pélvicas e mielite transversa, estas últimas consequientes a injeções em veias e artérias, não foram mencionadas pela nossa população em estudo.

Analisando os dados relativos à região $V G$, verifica-se que um $(2,08 \%)$ enfermeiro-docente e 7 (4,49\%) enfermeiros-hospitalares mencionaram complicações para essa região (Quadros 2-a e 2-b), todas entretanto discordantes dos autores estudados, pois estes não relatam nenhuma. A complicação referida pelo enfermeiro-docente "problemas neurológicos por lesão do nervo ciático e periósteo" e as mencionadas pelos enfermeiros-hospitalares, "paralisia do membro inferior por lesão do nervo ciático" (4) e "hematoma por punção de grandes vasos sangüíneos" (2) não são procedentes, pois os inúmeros estudos sobre essa região comprovaram a impossibilidade de qualquer vaso ou nervo relevante ser atingido com a utilização dessa região. Um dos enfermeiros-hospitalares mencionou a "dor" como complicação à utilização dessa região. Investigações clínicas a este respeito demonstraram não haver diferença significativa quanto à dor em relação a local (DG ou VG).

Analisando os dados relativos à região $F A L C$, observamos que suas complicações foram mencionadas por $2(4,7 \%)$ enfermeiros-docentes e por $11(7,05 \%)$ enfermeiros-hospitalares, sendo que todas foram especificas e concordantes com os autores consultados. As complicações referidas pelos enfermeiros-docentes foram dificuldade de deambulação por fibrose consequiente à falta de rodízio (1) e infiltrado por má absorção do medicamento (1) e as relatadas pelos enfermeiroshospitalares foram: hematoma por punção de grande vaso (1), lesão do nervo ciático (1), parestesia e paralisia por lesão nervosa (5), lesão do nervo femoral (1), traumatismo muscular com difícil recuperação (1), entumescimento local por má absorção do medicamento (1) e dor por injeção superficial (1).

Com relação à lesão de grandes vasos, apesar de alguns estudiosos mencionarem em suas publicações que esta região está livre 
de grandes vasos, outros relatam possibilidade de lesão de vasos importantes, por punção equivocadamente localizada na porção mediana da coxa, ou por acidente embólico da artéria femoral superficial resultante da transfixação da coxa por punção com agulha muito longa.

Quanto à possibilidade de lesão do nervo ciático nessa região, ela pode ser conseqüente à aplicação muito dorsal ou muito próxima à zona de flexão da coxa.

Lesões do nervo femoral foram minuciosamente estudadas e foram tidas como conseqüentes à utilização de agulhas de comprimento superior a $2,5 \mathrm{~cm}$.

Fibroses locais foram encontradas nas investigações realizadas em toxicômanos e foram tidas como consequientes a injeções repetidas. As infiltrações dolorosas podem ser devidas à introdução de grande volume de solução.

Lesões acidentais do nervo femoral cutâneo causam distúrbios sensoriais, dor momentânea e possível anestesia da pele na região inervada pelo nervo lesado.

A contratura do quadríceps femoral, não mencionada por nenhum dos dois grupos de enfermeiros, é analisada pelos que estudaram a utilização desta região para recém-nascidos e crianças pequenas; tais autores relatam casos de contratura do quadríceps femoral explicando-a como conseqüiente à ruptura do músculo pela agulha, com necrose, fagocitose e regeneração das fibras musculares no local da punção, além de isquemia local e conseqüente necrose muscular devido ao fato de que o medicamento injetado combinado com o edema local e pequena hemorragia pode comprimir as fibras musculares e capilares.

\section{CONCLUSOES}

Em um grupo de 48 enfermeiros-docentes das Escolas de Enfermagem do Município de São Paulo e de 156 enfermeiros-hospitalares dos principais hospitais que servem de campo de estágio a essas escolas, os resultados do levantamento sobre as regióes utilizadas para a aplicação de injeção IM, sua localização, diferenciação da escolha 
quanto ao sexo e idade e conhecimento sobre contra-indicações e complicações, conduzem às seguintes conclusões:

1 - as regiões $D$, FALC e DG são as preferencialmente utilizadas pelos enfermeiros-docentes, nas proporções de $89,59 \%$, $89,58 \%$ e $85,42 \%$ respectivamente, e as D, DG e FALC pelos enfermeiros-hospitalares, nas proporções de $96,13 \%, 79,35 \%$ e $60,65 \%$ respectivamente;

2 - os locais de aplicação das injeções IM nas diferentes regiões (D, DG, VG e FALC) mais utilizadas ou indicadas são anatomicamente corretos nas seguintes proporções:

a - enfermeiro-docente: D $(81,40 \%)$, DG $(63,41 \%)$, VG $(52,38 \%)$ e FALC $(69,77 \%)$;

b - enfermeiro-hospitalar: D $(77,85 \%)$, DG $(64,23 \%)$, VG $(50,00 \%)$ e FALC $(44,68 \%)$;

3 - a escolha da região para aplicação de injeção IM segundo os enfermeiros de ambos os grupos depende da idade, na proporção de $83,33 \%$ para os enfermeiros-docentes e de $82,69 \%$ para os enfermeiros-hospitalares, e independe do sexo;

4 - os enfermeiros-docentes e os enfermeiros-hospitalares não conhecem pàra cada uma das regiões de aplicação de injeção IM, todas as contra-indicações e complicações mencionadas pelos autores consultados e por nós utilizadas como critério de avaliação de conhecimento;

5 - a região VG, apesar de ser considerada pelos diversos autores consultados como a mais segura $e$ indicada para qualquer faixa etária e condição do cliente, é a menos utilizada pelos enfermeiros-docentes $(43,75 \%)$ e pelos enfermeiros-hospitalares $(1,29 \%)$.

CASTELLANOS, B. E. P. Study about the regions for intramuscular injections. Rev. Esc. Enf. USP, 11 (3): 261-324, 1977.

Administration of drugs by intramuscular injections is a nursing procedure. The choice of the sites to be utilized need to be considered regarding advantages and disadvantages of each local. $A$ data colection was started to know about the most utilized sites by nursing teachers and the hospital nurses, and the local pointed out by them for needle punction. It was verified that there is any differen- 
tiation in the choice of sites according the patient's age and sex and the knowledge of contraindications and complications of each sites for intramuscular injections. The data concluded that deltoidea, dorsogluteal and lateral thigh regions were the preferable one for both groups of nurses and the locations were not always anatomically right; for the choice of the site was considered the patient's age by $80 \%$ of the population. Only some mentioned contraindications and complications were according to consulted authors. The ventrogluteal region, supposed as the most save and suitable one by the authors, was the less mentioned by both groups of nurses.

\section{REFERENCIAS BIBLIOGRÁFICAS}

1. CHEZEM, J. L. - Multiple intramuscular injection: effects of mechanical trauma tissue and clearance rate of $I^{131}$ hippuran. Nurs. Res. 22: 138-43, Mar./Apr., 1973.

2. INTRAMUSCULAR injections. New York, Wyeth Laboratories, 1959.

3. HOCHSTETTER, A. - Uber die intraglutäale injektion, ihre Komplikationen und dereh verhütung. Schweis. Med. Wschr., 84: 1226-27, 1954.

4. HORN, B. J. - Intramuscular injections. Irish. Nurs. Hosp. World., 34 : 4, Jan., 1968.

5. HORTA, W. A. - Necessidades humanas básicas: considerações gerais. Enf. Novas Dimens., 1 (5): 267, 1975.

6. HORTA, W. A. \& TEIXEIRA, M. S. - Injeções parenterais. Rev. Esc. Enf. USP, 7 (1): 46-79, mar., 1973.

7. MARCONDES, E. - Pediatria - doutrina e ação. São Paulo, Savier, 1972. p. 66.

8. SCHMIDT, R. Von - Beitrag zur intramuskulären injektion. Helv. med. Acta, 24 : 561-86, 1957.

9. SUTTON, A. L. - Bedside nursing techniques in medicine and surgery. 2, ed. Philadelphia, Saunders, 1969.

10. TALBERT, J. L. et al. - Gangrene of the foot following an IM injection in the lateral thigh; a case report with recomendations to prevention. J. Pediat., 70: 110-14, Jan., 1967.

11. WEMPE, B. W. - The new and the old intramuscular injection sites. Am. J. Nurs., 61 : 56-7, Sep., 1961.

12. ZELMAN, S. - Notes on techniques injections. Am. J. Med. Sci., 241 : 563-66, 1961. 


\begin{abstract}
ANEXO 1
Prezado colega:

Estamos realizando uma pesquisa, como parte de nosso trabalho na Universidade de São Paulo. Nosso objetivo é verificar quais são as regiões mais utilizadas para a aplicação de injeção por via intramuscular e quais os critérios de escolha destes diferentes locais.
\end{abstract}

Como a finalidade deste nosso trabalho de pesquisa é a de dar subsídios para a avaliação de programas de ensino de eścolas de enfermagem é de máxima importância que as respostas sejam pessoais e individuais e por isto rogamos que não haja consulta interpessoal ou bibliográfica para o preenchimento deste questionário. Só assim os dados serão fidedignos e poderão ser analisados como representativos de uma situação real.

Estamos conscientes das vantagens de uma entrevista pessoal quanto à maior segurança na correção dos dados levantados mas as limitações de tempo, suas e nossas, não nos permitem utilizar esta técnica e a confiança profissional nos dá a liberdade de lançar mão deste questionário como instrumento de pesquisa.

Agradecemos o tempo que nos dispensará e a exatidão nas respostas, pois sua colaboração é essencial para a validade de nossa investigação.

Permitimo-nos ainda solicitar a mais breve devolução deste questionário preenchido para podermos desenvolver nosso projeto em tempo hábil. 


\section{QUESTIONARIO}

1 - Por favor, nas regiões que você comumente utiliza, assinale 0 local exato em que costuma aplicar a injeção intramuscular.

FACE ANTERO-LATERAL DA COXA
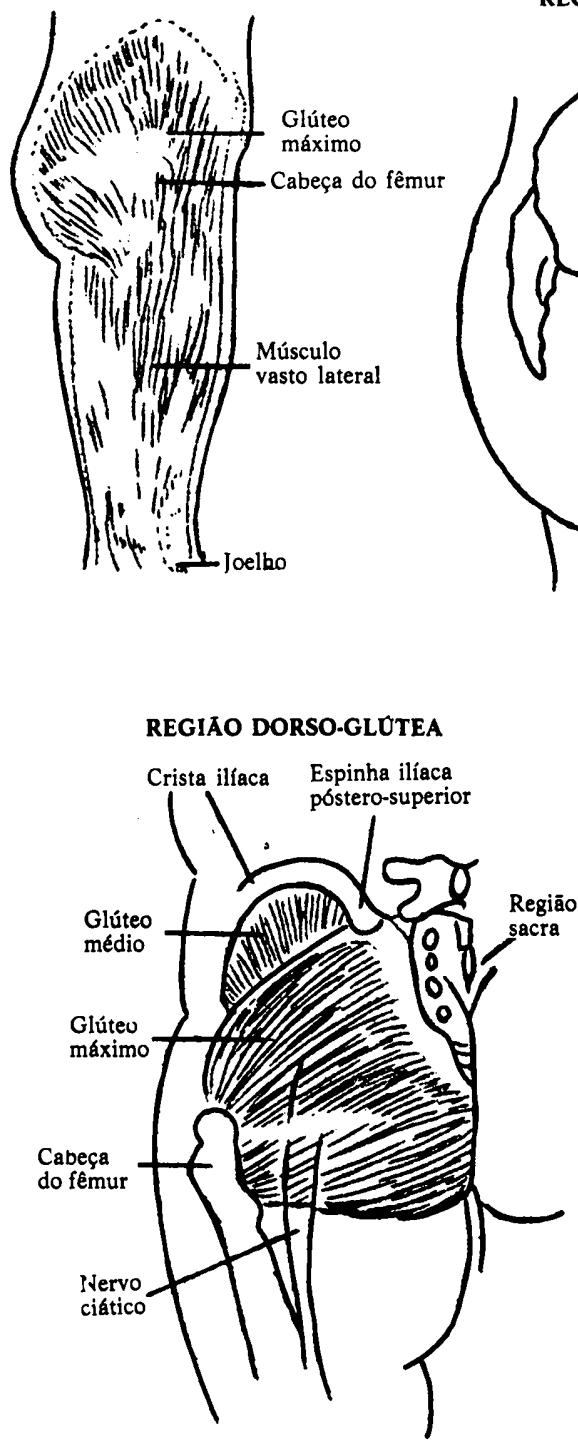

REGIĀO VENTRO-GLÚTEA

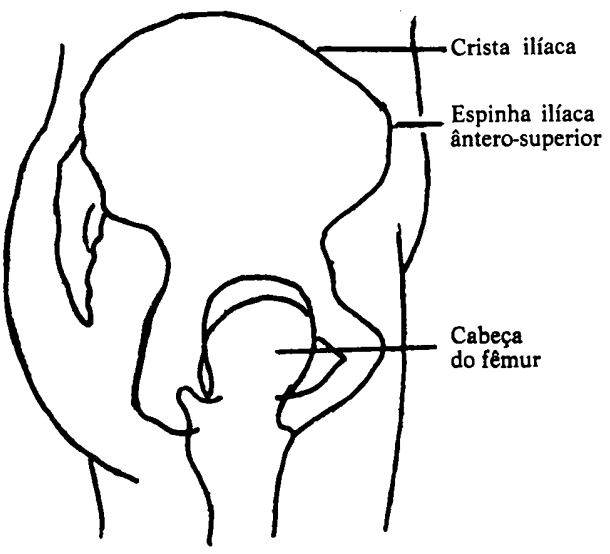


2 - Citaremos agora uma série de regiões que são utilizadas para a administração de medicamentos por via intramuscular. Dentre estas regiões qual a que tem tido oportunidade de utilizar ou orientar alguém na sua utilização?

\section{Região}

- R. glútea ( = nádegas)

- R. deltóide (= braço)

- R. dorso-glútea (= quadrante superior externo da região glútea)

- R. ventro-glútea (= R. de Hochstetter)

- Face ântero-lateral

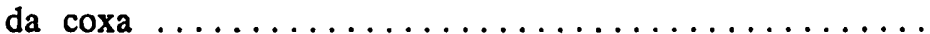

3 - Entre as regiões acima mencionadas existe alguma(s) que não conhece?

Sim Não

4 - (CASO SIM) - Qual(is) não conhece?

5 - Faz alguma diferenciação de região de aplicação, de acordo com o sexo do cliente?

$\operatorname{Sim}$

Não

6 - (CASO SIM) - Como faz esta diferenciação? 
Sexo

Masculino Feminino

Região

Glútea

Deltóide

Dorso-glútea

Ventro-glútea

Face ântero-lateral da coxa

7 - Faz alguma diferenciação de região de aplicação, de acordo com a idade do cliente?

$\operatorname{Sim} \ldots \ldots \ldots$

Não...$\ldots \ldots$

8 - (CASO SIM) - Em que faixa de idade você costuma indicar cada uma das regiões abaixo citadas para a aplicação da injeção intramuscular?

\begin{tabular}{ll}
\hline \multicolumn{1}{c}{ Região } & Idade \\
\hline Glútea & \\
\hline Deltóide \\
\hline Dorso-glútea \\
\hline Ventro-glútea \\
\hline Face ântero-lateral da coxa \\
\hline
\end{tabular}

9 - Existe alguma(s) região(ões) entre as acima citadas que conhece mas não teve oportunidade de utilizar? 
10 - (CASO SIM) - Qual(is)?

11 - (CASO SIM) - Teve conhecimento da indicação desta região para aplicação de injeção IM:

— por informação oral de alguém

- observou alguém utilizar esta região

- leu em alguma publicação sobre o assunto

- outro

12 - Por que não a utilizou até o momento?

13 - Tem conhecimento de alguma contra-indicação no uso de determinada região?

Sim Não

14 - (CASO SIM) - Qual(is)?

Região

Contra-indicação

Glútea

Deltóide

Dorso-glútea

Ventro-glútea

Face ântero-lateral da coxa 
15 - Tem conhecimento de alguma complicação no uso de determinada região (que não seja por problemas de assepsia)?

$\operatorname{Sim} \ldots \ldots \ldots$

Não ..........

$$
16 \text { - (CASO SIM) - Qual(is)? }
$$

Região

\section{Complicação}

Glútea

Deltóide

Dorso-glútea

Ventro-glútea

Face ântero-lateral da coxa

Sabemos que o tempo que nos dispensou the é precioso. Gostariamos de transmitir-lhes nossos agradecimentos e lhe assegurar que suas informaçōes serão de grande utilidade para nossa pesquisa.

OBSERVAÇOES PESSOAIS DO ENTREVISTADO - 
ANEXO 2

QUADRO 1-a

CONTRA-INDICAÇOES CITADAS PELOS ENFERMEIROSDOCENTES (28 DOCENTES)

REGIÃO CONTRA-INDICAÇÃO

- grande quantidade de líquido/medicamento

- em casos de mastectomia no respectivo lado

- em casos de lesão dermatológica local

- quando houver paralisia do membro, atrofia muscular, comprometimento circulató-

DELTOIDE (D) rio

- para crianças (pequeno volume muscular)

- devido à possibilidade de lesão de nervos e vasos (adulto) . 1

- em virtude do pequeno volume muscular e inervação superficial desta região 1

- em virtude da localização do nervo radial 


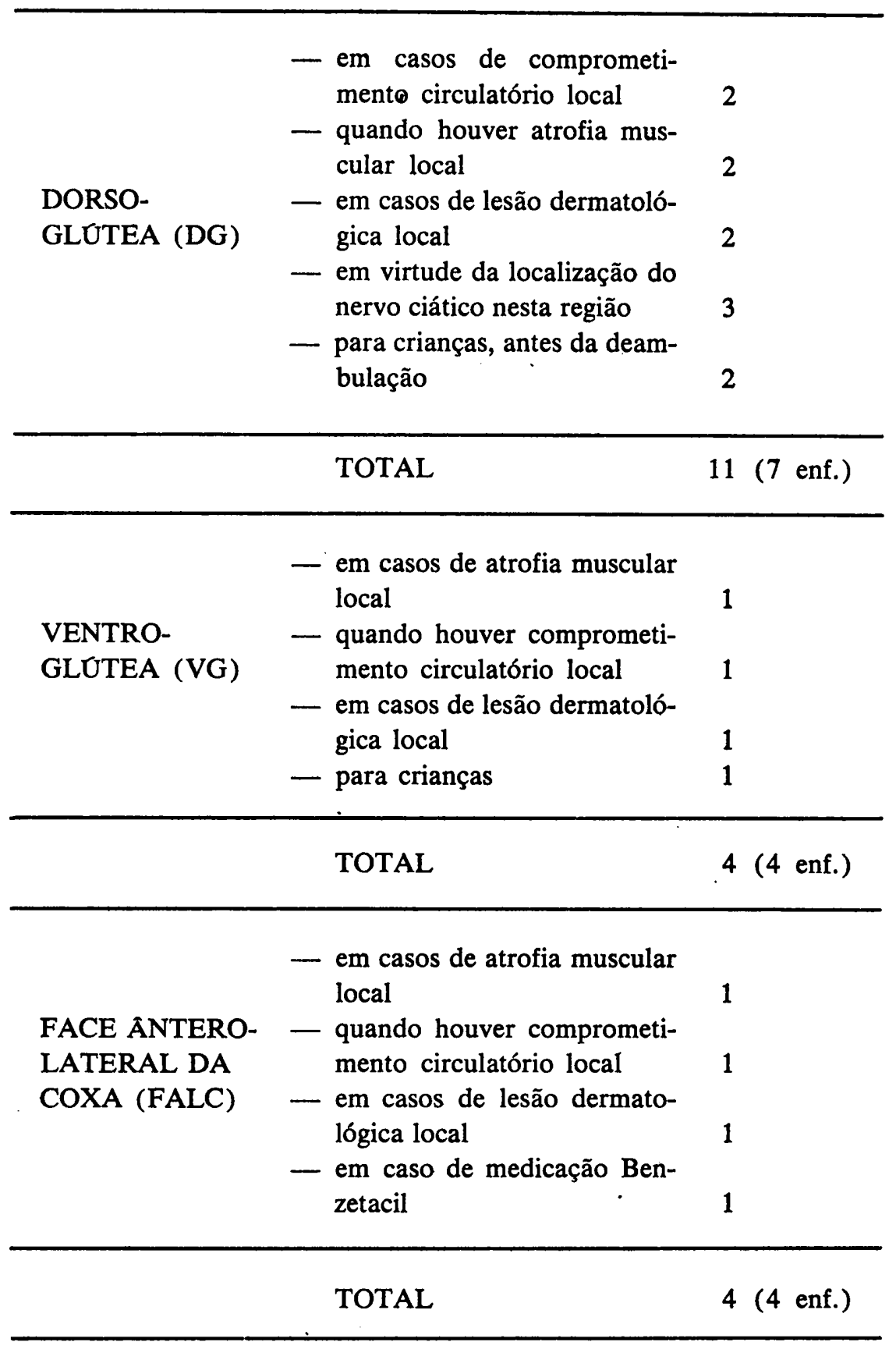


A NEXO 2

QUADRO 1-b

CONTRA-INDICAÇOES CITADAS PELOS ENFERMEIROSHOSPITALARES (69 ENFERMEIROS)

\begin{tabular}{|c|c|c|}
\hline REGIÃO & CONTRA-INDICAÇÃO & FREQUENCIA \\
\hline \multirow[t]{2}{*}{ DELTOIDE (D) } & $\begin{array}{l}\text { - em casos de grande quanti- } \\
\text { dade de líquido/medica- } \\
\text { mento } \\
\text { - em casos de medicamentos } \\
\text { oleosos/dolorosos } \\
\text { - em casos de número grande } \\
\text { de aplicações; edema ou es- } \\
\text { cara local; lesão dermatológi- } \\
\text { ca local } \\
\text { - conforme faixa etária: } 0 \text {--10 } \\
\text { anos } \\
\text { - em casos de caquexismo, } \\
\text { magreza excessiva } \\
\text { - em virtude da localização de } \\
\text { grandes vasos nesta região } \\
\text { - Benzetacil } \\
\text { - nos casos de injeção IM pro- } \\
\text { funda } \\
\text { - para crianças, devido ao pe- } \\
\text { queno volume muscular }\end{array}$ & $\begin{array}{l}2 \\
2 \\
6 \\
1 \\
1 \\
2 \\
2\end{array}$ \\
\hline & TOTAL & 26 (20 enf.) \\
\hline
\end{tabular}


- em virtude da localização do nervo ciático nesta região 4

- em casos de número grande de aplicações 2

- em casos de lesão dermatológica local 2

- em casos de quantidades maiores de $5 \mathrm{ml} \quad 1$

- em virtude de localização de

DORSOGLUTEA (DG) grandes vasos nesta região 1

- conforme faixa etária lactentes 1 crianças 2

- em casos de caquexismo, magreza excessiva 1

- utilização do ângulo inferior do quadrante superior externo 1

TOTAL

- em virtude da localização do nervo ciático nesta região

- em virtude da localização de nervos, artérias importantes nesta região; articulação coxo-femoral muito próxima 1

- para aplicação de vacinas 1

VENTROGLUTEA (VG)

- em casos de lesão dermatológica local

- conforme faixa etária: 0 - 10 anos

- em casos de caquexismo, magreza excessiva 1

- devido a proximidade de alças intestinais

- total (nunca deve ser utilizada) 
- para o sexo masculino devido ao excesso de pelos nesta região

- conforme faixa etária $\begin{array}{cc}\text { adultos } & 1 \\ \text { crianças } & 1\end{array}$

- em casos de lesão dermatológica e comprometimento

FACE ÂNTERO- neurológico ou vascular local 2 LATERAL DA - em virtude da localização do COXA (FALC) nervo ciático nesta região 1

- em virtude da localização do nervo femoral 1

- em casos de medicamentos de difícil absorção 1

- em virtude da localização de importantes vasos sangüíneos nesta região

- em casos de quantidades superiores a $5 \mathrm{ml} 1$

- por ser região muito dolorosa 
ANEXO 3

QUADRO 2-a

COMPLICAÇŌES CITADAS PELOS ENFERMEIROSDOCENTES (27 DOCENTES)

REGIÃO

CONTRA-INDICAÇÃO FREQUENCIA

- paralisia da articulação escápulo-umeral por lesão do nervo circunflexo 1

- necrose e dores intensas no

DELTOIDE (D) local 1

- hematoma e comprometimento vascular por lesão da artéria umeral 1

- hipotrofia muscular, paralisia do braço e antebraço 3

TOTAL

6 (5 enf.)

DORSO-

GLUTEA (DG)
- parestesia e paralisia do membro inferior por lesão do nervo ciático 
VENTRO-

GLUTEA (VG)
- problemas neurológicos por lesão do nervo ciático e periósteo

- dificuldade de deambular

FACE ÂNTERO- devido a lesão por falta de LATERAL DA $\quad$ rodízio (fibrose) 1

COXA (FALC) - por má absorção do medicamento infiltrado (infiltrados) 1 


\section{A NEXO 3}

QUADRO 2-b

COMPLICAÇÕES CITADAS PELOS ENFERMEIROSHOSPITALARES (67 ENFERMEIROS)

\begin{tabular}{|c|c|c|}
\hline REGIÃO & CONTRA-INDICAÇÃO & FREQUUENCIA \\
\hline \multirow[t]{2}{*}{ DELTOIDE (D) } & $\begin{array}{l}\text { - nódulos e infiltrados por } \\
\text { má absorção do medica- } \\
\text { mento e grande quantidade } \\
\text { de solução } \\
\text { - traumatismo muscular em } \\
\text { criança } \\
\text { - lesão do nervo radial } \\
\text { - comprometimento circulató- } \\
\text { rio por lesão vascular }\end{array}$ & $\begin{array}{l}9 \\
1 \\
1 \\
1\end{array}$ \\
\hline & TOTAL & 12 (12 enf.) \\
\hline \multirow[t]{2}{*}{$\begin{array}{l}\text { DORSO- } \\
\text { GLUTEA (DG) }\end{array}$} & $\begin{array}{l}\text { - paralisia, dor, encurtamento } \\
\text { do membro inferior por lesão } \\
\text { do nervo ciático } \\
\text { - infiltrados por má absorção } \\
\text { do medicamento }\end{array}$ & $\begin{array}{r}10 \\
2\end{array}$ \\
\hline & TOTAL & 12 (11 enf.) \\
\hline
\end{tabular}


- paralisia do membro inferior

VENTROpor lesão do nervo ciático

4

GLOTEA (VG) - hematoma por punção de grandes vasos sangüíneos

2

- dor 1

TOTAL

7 (5 enf.)

- parestesia, paralisia por lesão nervosa (nervo femoral) 5

- traumatismo muscular com difícil recuperação 1

- entumescimento local por

FACE ÂNTEROmá absorção do medica-

LATERAL DA mento

1

COXA (FALC)

- hematoma por punção de grande vaso sangüíneo 1

- lesão do nervo femoral 1

- lesão do nervo ciático 1

- dor, quando a injeção for aplicada superficialmente 1 